Article

\title{
Utility Indifference Valuation for Defaultable Corporate Bond with Credit Rating Migration
}

\author{
Zhehao Huang ${ }^{1} \mathbb{D}$, Zhenghui $\mathrm{Li}^{1}{ }^{1}$ and Zhenzhen Wang ${ }^{2, *}$ \\ 1 Guangzhou Institute of International Finance, Guangzhou University, Guangzhou 510405, China; \\ zhehao.h@gzhu.edu.cn (Z.H.); lizh@gzhu.edu.cn (Z.L.) \\ 2 School of Mathematics, Sun Yat-sen University, Guangzhou 510275, China \\ * Correspondence: wangzhzh29@mail.sysu.edu.cn
}

Received: 16 October 2020; Accepted: 13 November 2020; Published: 15 November 2020

\begin{abstract}
Credit risk modeling by debt pricing has been a popular theme in both academia and practice since the subprime crisis. In this paper, we devote our study to the indifferent price of a corporate bond with credit risk involving both default risk and credit rating migration risk in an incomplete market. The firm's stock and a financial index on the market as tradable assets are introduced to hedge the credit risk, and the bond price is determined by the indifference of investors' utilities with and without holding the bond. The models are established under the structural framework and result in Hamilton-Jacobi-Bellman (HJB) systems regarding utilities subject to default boundary and multiple migration boundaries. According to dynamic programming theory, closed-form solutions for pricing formulas are derived by implementing an inverted iteration program to overcome the joint effect of default and multiple credit rating migration. Therefore, with the derived explicit pricing formulas for the corporate bond, the models can be easily applied in practice, and investors can generate their strategies of hedging the credit risk by easily analyzing the impacts of the parameters on the bond price.
\end{abstract}

Keywords: utility indifference valuation; defaultable corporate bond; credit rating migration; structural model; dynamic programming

\section{Introduction}

Corporate bonds play important roles in the financing channels of firms. They are very popular in financial markets. Corporate bonds contain credit risk, which has been empirically verified as seriously influential on financial stability and the business cycle [1-3]. Especially after the financial crisis of 2008 and the European debt crisis of 2010, credit information has been more attractive to market participants. Investors demand trading strategies to hedge credit risk, and regulators are anxious to control credit risk contagion [4-6]. Credit risk refers not only to default risk [7-9], but also to credit rating migration risk [10-12], where the latter has received more and more attention. Credit ratings influence the prices of corporate bonds [13-15]. How do we price the corporate bond in different credit ratings, and how does the bond change its price when its rating migrates? These problems deserve answers. Accordingly, in this paper, we focus on the valuation of defaultable corporate bonds with credit rating migration, where the bond is supposed to be a zero-coupon.

We assume that the market is incomplete. Thus, if the corporate bond is considered as the claim written on the firm's asset value, theoretically, there is no longer a unique claim price. In this situation, the utility indifference valuation methodology, initiated by Hodges and Neuberger [16], is considered as a useful tool to ensure the unique claim price in the incomplete market, with the advantage including economic justification and the incorporation of risk aversion. Thus, in this paper, the prices of the corporate bonds are determined according to the utility indifference principle. Meanwhile, the credit 
risks, including the default risk and credit rating migration risk, are modeled under the structural framework, which was originated by Merton [17] and extended by Black and Cox [18]. The default is triggered if the firm's value falls below some given threshold, while the credit rating migrates if the proportion of the firm's debt and asset value passes the threshold.

When an investor wants to decide the indifferent price of the corporate bond written on the non-tradable firm's asset value, it is suggested that he/she trade a tradable and correlative asset on the market to hedge the credit risk of such a corporate bond. In this paper, we follow Liang and Jiang [19] by considering two natural candidates, the firm's stock and a financial index. As the first-passage-time model of Black and Cox [18] is used, as the default time is also the collapsing time of the firm, if the investor trades the firm's stock, he/she fails to go on trading the firm's stock afterwards. After the default, the investor has to invest the remaining wealth into a bank account earning a risk-free interest rate. On the other hand, if the investor trades a financial index instead, he/she will lose some money at the default time. However, he/she can continue to trade the financial index afterwards. After the default, the investor continues to trade the financial index on the market with a shifted initial wealth depending on his/her loss from the firm's default. In addition, another subtle difference between trading the firm's stock and trading the financial index is that the stock price shows heterogeneous volatilities, infected by the firm's asset value due to the credit rating migration, while the financial index is supposed to be robust with regard to the credit rating migration. The effect of credit rating migration risk was not involved in the consideration of Liang and Jiang [19].

The first attempt to model credit rating migration in an incomplete market is attributed to Liang et al. [20], where the overall credit region was divided into two ratings, and this resulted in only one migration boundary. To obtain the closed-form solution for the bond price and analyze the effect of credit rating migration risk, Liang et al. [20] exogenously imposed an additive boundary condition on the migration boundary. In reality, for example, Standard \& Poor's, one of the worldwide credit rating institutes, has detailed rating scales, such as $\mathrm{A}, \mathrm{BBB}$, and $\mathrm{BB}$, even with positive or negative signs, known as notch signs [2]. Accordingly, in this paper, we divide the credit region into $n$ credit ratings, where $n$ is supposed to be an arbitrary integer. Perhaps such extension looks like a slight and trivial change. However, technically, this really causes some trouble in deriving a closed-form solution for the bond price. As there are $n$ ratings assessing the firm's credit, this produces $n-1$ credit rating migration boundaries. Thus, it is difficult to exogenously impose $n-1$ boundary conditions on the migration boundaries, similar to Liang et al. [20]. This may easily lead to the ill-posedness of the model, and we cannot obtain the closed-form solution for the bond price. We solve this problem by following the assumption from Black and Cox [18], i.e., the first-passage-time model to capture the default event, rather than Merton's model [17] used by Liang et al. [20], where default is only allowed to happen at maturity. The usage of the first-passage-time model endogenously generates a default boundary. Meanwhile, in this paper, the credit rating migration is modeled by the dynamic proportion of the firm's debt and the asset value [21,22], which means that the migration boundaries depend not only on the firm's asset value, but also on the bond price. Finally, we obtain the closed-form solution for the bond pricing model by taking an inverted iteration program, i.e., the solving program is started at the lowest credit rating region as it is bounded by the default boundary and finished in the highest credit rating region.

The rest of the paper is organized as follows. Section 2 provides a literature review. In Section 3 , the overall modeling framework is presented, involving some necessary assumptions, and the Hamilton-Jacobi-Bellman (HJB) equation system is derived. In Section 4, the closed-form solution of the HJB system is obtained by an inverted iteration according to the utility indifference pricing principle. In Section 5, we conclude the paper.

\section{Literature Review}

The corporate bond can be regarded as a contingent claim written on the firm's asset value. In general, claim pricing has two equivalent approaches in a complete market, replication and 
hedging $[16,23]$. A uniquely fair price consistent with no-arbitrage can be determined through perfect replication or hedging. However, few situations are complete in reality. Market frictions like transaction costs, non-liquid assets, and portfolio constraints lead to impossibly perfect replication. Theoretically, there is no longer a unique price in such situations. Thus, the utility difference valuation methodology is used to ensure the claim price is unique in the incomplete market [16]. The idea of utility indifference valuation is to look for a price at which the buyer (or writer) of the derivative is indifferent in terms of maximum utility, no matter whether he/she holds the derivative. In fact, this approach leads us to solving optimization problems in the incomplete market by using the dynamic programming approach. Henderson [24] presented the solutions for the power utility and exponential utility respectively under Markovian framework, where the pricing formula for the exponential utility was derived and extended to the price under the power utility as well. Musiela and Zariphopoulou [25] also solved the explicit price under the exponential utility, while Zariphopoulou [26] solved a slightly different problem under the power utility, where the Cole-Hopf transformation was introduced and the door to the further development of indifference pricing was widely opened. Liang and Jiang [19] applied the utility indifference valuation method to corporate bond pricing with the default probability. The indifferent price and hedging strategies were obtained. Liang et al. [20] also priced corporate bonds in the incomplete market by the utility indifference principle, but with the credit rating migration probability, obtaining closed-form solution for the bond price as well. More papers on indifference valuation are Porchet et al. [27], Benedetti and Campi [28], Li et al. [29], and so forth.

The model of credit risk in our paper is established under the structural framework. Traditional models for credit risk modeling are classified into two broad categories, respectively: the reduced-form approach and the structural approach. The reduced-form approach, originally developed by Duffie and Singleton [30] (see also Jarrow and Turnbull [31]), follows the assumption that information flows can be reduced to the observations of a random time representing a firm's default event. It concerns exogenous reasons rather than the firm's capital structure and asset value. The default time is modeled by introducing a hazard rate (default intensity) [32,33]. The structural approach refers directly to the endogenous factors like the capital structure and asset value process. Merton [17], who was the originator of structural models, presumed that the firm's asset value process follows a geometric Brownian motion and regarded the corporate bonds as contingent claims on the firm's asset value. It assumes that a firm's default is triggered by an event, where the asset value decreases until it is lower than the debt at maturity. Following the pioneering work of Merton [17], Black and Cox [18] developed another structural model that enables default events to occur at any time before debt maturity. They applied the Black-Scholes formula in option pricing theory to corporate bonds with indenture provisions and also showed that it can be used to analyze the effects of indenture provisions on a firm's default events. Extended studies of the first-passage-time model are Leland [34], Longstaff and Schwartz [35], Leland and Toft [36], Briys and de Varenne [37], and so forth.

Both structural and reduced-form approaches begin to demonstrate only the credit default event. For modeling credit rating migration, a commonly adopted approach is the Markov chain, which is captured by a transition intensity matrix, coming from general statistical data $[10,38,39]$. Then, the reduced-form framework can be naturally developed for dynamic credit rating migration processes $[32,40,41]$. However, in reality, empirical studies have verified that the firm's asset value plays an important role in the credit rating migration process $[10,11]$. Specifically, it is an inadequacy of the reduced-form model, which assumes that the credit events are independent of the behaviors of the firm itself. A structural model works by overcoming such an inadequacy of the reduced-form model. Furthermore, the migration boundary is indicated by the structural model, by which investors can get more credit information more conveniently. Liang et al. [20] started to model and analyze credit rating migration risk by the structural model based on Merton [17]. They divided the firm's asset value into high and low rating regions by setting a predetermined migration threshold, where the firm's asset value follows different stochastic processes. As the threshold dividing the credit ratings is usually not predetermined, Hu et al. [21] determined the migration boundary by the dynamic proportion 
between the firm's debt and the asset value, which results in a free boundary problem. Subsequently, Liang et al. [22] incorporated a risk discount factor, which measures the sensibility of credit rating migration to the proportion of the debt and asset value, into the model and showed a profile of an asymptotic traveling wave exists in the free boundary problem. Liang et al. [42] and Yin et al. [43] considered the situations of the time-varying risk-free interest rate [44,45]. Wu and Liang [46] provided some numerical results for multiple credit rating migration problems. More papers on credit rating migration modeling by the structural approach are Wu and Liang [47], Wu et al. [48], Wang et al. [49], Huang et al. [50,51], Liang and Zhou [52], and so forth.

We model the credit risk, involving default risk and credit rating migration risk, by using the Black and Cox's structural model (known as the first-passage-time model) and obtain the explicit formula of the corporate bond price with both default and credit rating migration probabilities in an incomplete market according to the utility indifference principle. Our work contributes to the literature on the indifference pricing methodology, the structural approach, and credit rating migration modeling.

\section{Modeling}

In this section, we develop the structural model to embed the utility indifference valuation framework for the defaultable corporate bond with credit rating migration. We follow the Black-Cox assumption on the default risk (Black and Cox [18] and Liang and Jiang [19]). The credit rating migration risk is captured according to Hu et al. [21] and Liang et al. [22], where the firm's credit rating is downgraded or upgraded as the proportion of the firm's debt and the firm's value passes some pre-set threshold.

\subsection{Assumptions}

\subsubsection{The Market}

Let $(\Omega, \mathscr{F}, \mathbb{P})$ be a complete probability space. The market is built on four assets: a risk-free asset with constant interest rate $r$, a financial index, a stock, and a corporate bond, the latter two of which are issued by the firm. Let $S_{t}$ be the stock's value at time $t$, which satisfies:

$$
d S_{t}=\mu_{S} S_{t} d t+\sigma_{S} S_{t} d B_{t}^{S}
$$

where the constants $\mu_{S}$ and $\sigma_{S}$ represent the appreciation rate and the volatility of the stock, respectively, and $\left(B_{t}^{S}\right)_{t \geq 0}$ is the Brownian motion with its natural filtration $\left\{\mathscr{F}_{t}^{S}\right\}_{t \geq 0}$. The financial index, whose price satisfies:

$$
d P_{t}=\mu_{P} P_{t} d t+\sigma_{P} P_{t} d B_{t}^{P}
$$

is traded on the market and is non-defaultable, where the constants $\mu_{P}$ and $\sigma_{P}$ represent the appreciation rate and the volatility of the stock, respectively, and $\left(B_{t}^{P}\right)_{t \geq 0}$ is the Brownian motion with its natural filtration $\left\{\mathscr{F}_{t}^{P}\right\}_{t \geq 0}$.

\subsubsection{The Firm}

The firm's asset value, denoted by $\left(V_{t}\right)_{t \geq 0}$, is observed from the balance sheet, but cannot be traded on the market. We suppose that its value satisfies:

$$
d V_{t}=\mu_{V} V_{t} d t+\sigma_{V} V_{t} d B_{t}^{V}
$$

where the constant $\mu_{V}$ is the surplus of the expected return, that is the expected return subtracted by dividends, and $\sigma_{V}$ is the volatility of the firm's value. $\left(B_{t}^{V}\right)_{t \geq 0}$ is the Brownian motion, which generates 
the filtration $\left\{\mathscr{F}_{t}^{V}\right\}_{t \geq 0}$. The firm's value $V$ is correlated with its stock price $S$ and the financial index price $P$. Their correlations are modeled by the correlations of the associated Brownian motions:

$$
\operatorname{Cov}\left(d B_{t}^{V}, d B_{t}^{S}\right)=\rho_{V S} d t, 0 \leq \rho_{V S} \leq 1,
$$

and:

$$
\operatorname{Cov}\left(d B_{t}^{V}, d B_{t}^{P}\right)=\rho_{V P} d t,-1 \leq \rho_{V P} \leq 1 .
$$

It is natural to assume that the firm's value $V$ and the stock price $S$ are positively correlated. However, the financial index $P$ may include financial institutions that are the counterparty of such a firm. Hence, the correlation between $V$ and $P$ might be negative. We write $\mathscr{F}_{t}=\mathscr{F}_{t}^{V} \vee \mathscr{F}_{t}^{S} \vee \mathscr{F}_{t}^{P}$ for $t \in[0, T]$.

\subsubsection{Default Risk}

We suppose that the corporate bond has face value $F$ and maturity $T$. Its price at time $t$ is denoted by $\Theta_{t}$, which is the key quantity we would like to value in this paper. We follow the Black-Cox assumption on the contract. Default will occur at the first time when the firm's value $V$ falls below the default barrier, denoted by $D_{t}$, which evolves as:

$$
D_{t}=D e^{-\alpha(T-t)}
$$

where $D$ and $\alpha$ are positive constants. The default time is then the following stopping time:

$$
\tau_{D}=\inf \left\{t \in[0, T]: V_{t} \leq D_{t}\right\}
$$

and the payoff of the contract is:

$$
H_{\tau_{D} \wedge T}=\omega D_{\tau_{D}} 1_{\left\{\tau_{D} \leq T\right\}}+F 1_{\left\{\tau_{D}>T\right\}}
$$

where the constant $\omega \in[0,1]$ is the recovery rate that the firm will pay for the holders of the corporate bond when default occurs.

\subsubsection{Credit Rating Migration Risk}

We follow the assumption of Hu et al. [21] on the modeling of credit rating migration. The credit rating of the firm migrates at the first time the proportion of the firm's debt and the firm's value, denoted by:

$$
\ell_{t}=\frac{\Theta_{t}}{V_{t}}
$$

passes some pre-set threshold. Suppose that there are $n$ credit ratings considered in this paper and then $n-1$ thresholds dividing the credit region. Denote these thresholds by:

$$
0<\ell_{1}<\ell_{2}<\cdots<\ell_{n-2}<\ell_{n-1}<\infty,
$$

and then, the credit rating migration times are defined as follows:

$$
\begin{gathered}
\tau_{1}=\inf \left\{t \in[0, T]: \ell_{0}<\ell_{1}, \ell_{t} \geq \ell_{1}\right\}, \\
\tau_{i}=\inf \left\{t \in[0, T]: \ell_{0} \in\left(\ell_{i-1}, \ell_{i}\right), \ell_{t} \notin\left(\ell_{i-1}, \ell_{i}\right)\right\}
\end{gathered}
$$

for $i=2,3, \cdots, n-1$, and:

$$
\tau_{n}=\inf \left\{t \in[0, T]: \ell_{0}>\ell_{n-1}, \ell_{t} \leq \ell_{n-1}\right\}
$$


The volatility of the firm's value with a high credit rating is usually weaker than that with a low credit rating (Hu et al. [21]). Thus, denote by $\sigma_{V i}$ the corresponding volatility of the firm's value in the $i$ 'th credit rating, $i=1,2, \cdots, n$. These volatilities satisfy the order:

$$
0<\sigma_{V 1}<\sigma_{V 2}<\cdots<\sigma_{V n-1}<\sigma_{V n}<\infty .
$$

Meanwhile, the volatility of the firm's value may spill over to its stock. This results in that the volatility of the stock is also heterogeneous in different credit ratings of the firm. Denote by $\sigma_{S i}$ the volatility of the stock in the $i^{\prime}$ th credit rating, $i=1,2, \cdots, n$. They also satisfy the order:

$$
0<\sigma_{S 1}<\sigma_{S 2}<\cdots<\sigma_{S n-1}<\sigma_{S n}<\infty
$$

\subsubsection{The Investor}

The holder of the corporate bond has a CARAutility function, which depends on his/her terminal wealth $W$ :

$$
U(W)=-e^{-\gamma W}, W \in \mathbb{R},
$$

where $\gamma \geq 0$ denotes the risk aversion parameter. More general and practice utility functions, such as the mean-variance utility function [53], used in [54,55], can be approximated by this CARA utility function.

The investor with initial wealth $W$ invests in either the stock $S$ or the financial index $P$ by following the admissible trading strategy $\pi \in \mathcal{A}_{a d}[0, T]$ :

$$
\mathcal{A}_{a d}=\left\{\pi:[0, T] \times \Omega \rightarrow \mathbb{R}: \pi \text { is } \mathscr{F}_{t} \text {-adapted, self-financing and } \int_{0}^{T} \mathbb{E}\left[\pi_{t}^{2}\right] d t<\infty\right\} .
$$

If the investor invests in the stock $S$, then his/her wealth $W^{S}$ follows:

$$
\begin{aligned}
d W_{t}^{S} & =d\left(W_{t}^{S}-\pi_{t}\right)+d \pi_{t} \\
& =r\left(W_{t}^{S}-\pi_{t}\right) d t+\mu_{S} \pi_{t} d t+\sigma_{S} \pi_{t} d B_{t}^{S} \\
& =r W_{t}^{S} d t+\left(\mu_{S}-r\right) \pi_{t} d t+\sigma_{S} \pi_{t} d B_{t}^{S},
\end{aligned}
$$

where the wealth is divided into two parts: the first part $W_{t}^{S}-\pi_{t}$ is risk free, and the second part $\pi_{t}$ satisfies (1) by self-financing. Likewise, if the investor invests in the financial index $P$, then the wealth $W^{P}$ follows:

$$
d W_{t}^{P}=r W_{t}^{P} d t+\left(\mu_{P}-r\right) \pi_{t} d t+\sigma_{P} \pi_{t} d B_{t}^{P} .
$$

\subsection{Maximal Expected Utility Problem}

If the investor holds a corporate bond, he/she invests in either the stock $S$ or the financial index $P$ to hedge the credit risk (involving default risk and credit rating migration risk) from holding such a corporate bond. The indifference price of the corporate bond is determined by the comparison of two utility maximization problems with and without holding the corporate bond.

The first case is that the investor invests in the stock $S$. Suppose that the investor holds the corporate bond, i.e., he/she hedges the credit risk of the corporate bond by trading the stock $S$. The investor buys the corporate bond at time $t$ with the price $\Theta_{t}$ and invests in the stock with the remaining wealth $W_{t}^{S}-\Theta_{t}$. The investor faces both the default risk and credit rating migration risk during the time period $[t, T]$. If the firm defaults before migrating to another credit rating in the time period $[t, T]$, i.e., on the set $\left\{\tau_{D} \leq \min \left\{\tau_{i}, T\right\}\right\}$ for some $1 \leq i \leq n$, meaning that the firm is in the $i^{\prime}$ th credit rating at time $t$, the investor gets $W_{\tau_{D}}^{S}+H_{\tau_{D}}$. Since the firm collapses, the investor has no stock to trade after the default and then will put the remaining wealth $W_{\tau_{D}}^{S}+H_{\tau_{D}}$ into the bank account to earn the risk-free interest rate $r$. If the credit rating migrates before defaulting in the time period 
$[t, T]$, a virtual substitute termination happens, i.e., on the set $\left\{\tau_{i} \leq \min \left\{\tau_{D}, T\right\}\right\}$ for some $1 \leq i \leq n$, the contract is virtually terminated and substituted by a new one with a new credit rating. If both the default and credit rating migration do not happen before maturity, i.e., on the $\operatorname{set}\left\{\min \left\{\tau_{D}, \tau_{i}\right\} \geq T\right\}$ for some $1 \leq i \leq n$, the investor gets $W_{T}^{S}+H_{T}$ at maturity. Overall, the investor will maximize his/her utility:

$$
U_{1}^{S}(t, W, V)=\sup _{\pi \in \mathcal{A}_{a d}} \mathbb{E}\left[u_{1}^{S}+v_{1}^{S}+w_{1}^{S} \mid W=W_{t}^{S}-\Theta_{t}, V=V_{t}, \Theta_{t} \leq \ell_{1} V_{t}\right],
$$

where:

$$
\begin{gathered}
u_{1}^{S}=-\exp \left(-\gamma\left(W_{T}^{S}+H_{T}\right)\right) 1_{\left\{\min \left\{\tau_{D}, \tau_{1}\right\} \geq T\right\}}, \\
v_{1}^{S}=-\exp \left(-\gamma\left(e^{r\left(T-\tau_{D}\right)}\left(W_{\tau_{D}}^{S}+H_{\tau_{D}}\right)\right)\right) 1_{\left\{\tau_{D} \leq \min \left\{\tau_{1}, T\right\}\right\}} \\
w_{1}^{S}=U_{2}^{S}\left(\tau_{1}, W_{\tau_{1}}^{S}, V_{\tau_{1}}\right) 1_{\left\{\tau_{1} \leq \min \left\{\tau_{D}, T\right\}\right\}},
\end{gathered}
$$

and:

$$
U_{i}^{S}(t, W, V)=\sup _{\pi \in \mathcal{A}_{a d}} \mathbb{E}\left[u_{i}^{S}+v_{i}^{S}+w_{i}^{S} \mid W=W_{t}^{S}-\Theta_{t}, V=V_{t}, \ell_{i-1} V_{t} \leq \Theta_{t} \leq \ell_{i} V_{t}\right],
$$

where:

$$
\begin{aligned}
& u_{i}^{S}=-\exp \left(-\gamma\left(W_{T}^{S}+H_{T}\right)\right) 1_{\left\{\min \left\{\tau_{D}, \tau_{i}\right\} \geq T\right\}}, \\
& v_{i}^{S}=-\exp \left(-\gamma\left(e^{r\left(T-\tau_{D}\right)}\left(W_{\tau_{D}}^{S}+H_{\tau_{D}}\right)\right)\right) 1_{\left\{\tau_{D} \leq \min \left\{\tau_{i}, T\right\}\right.}, \\
& w_{i}^{S}=\left(U_{i+1}^{S}\left(\tau_{i}, W_{\tau_{i}}^{S}, V_{\tau_{i}}\right) 1_{\left\{\Theta_{\tau_{i}} \geq \ell_{i} V_{\tau_{i}}\right\}}+U_{i-1}^{S}\left(\tau_{i}, W_{\tau_{i^{i}}}^{S}, V_{\tau_{i}}\right) 1_{\left\{\Theta_{\tau_{i}} \leq \ell_{i-1} V_{\tau_{i}}\right\}}\right) 1_{\left\{\tau_{i} \leq \min \left\{\tau_{D}, T\right\}\right\}},
\end{aligned}
$$

for $i=2,3, \cdots, n-1$, and:

$$
U_{n}^{S}(t, W, V)=\sup _{\pi \in \mathcal{A}_{a d}} \mathbb{E}\left[u_{n}^{S}+v_{n}^{S}+w_{n}^{S} \mid W=W_{t}^{S}-\Theta_{t}, V=V_{t}, \Theta_{t} \geq \ell_{n-1} V_{t}\right]
$$

where:

$$
\begin{gathered}
u_{n}^{S}=-\exp \left(-\gamma\left(W_{T}^{S}+H_{T}\right)\right) 1_{\left\{\min \left\{\tau_{D}, \tau_{n}\right\} \geq T\right\}}, \\
v_{n}^{S}=-\exp \left(-\gamma\left(e^{r\left(T-\tau_{D}\right)}\left(W_{\tau_{D}}^{S}+H_{\tau_{D}}\right)\right)\right) 1_{\left\{\tau_{D} \leq \min \left\{\tau_{n}, T\right\}\right\}}, \\
w_{n}^{S}=U_{n-1}^{S}\left(\tau_{n}, W_{\tau_{n}}^{S}, V_{\tau_{n}}\right) 1_{\left\{\tau_{n} \leq \min \left\{\tau_{D}, T\right\}\right\}} .
\end{gathered}
$$

Suppose that the investor does not hold the corporate bond and only invests in the stock. As the stock is issued by the firm, the wealth of the investor is also exposed to both default risk and credit rating migration risk, despite he/she not investing in the corporate bond. The investor will maximize his/her utility:

$$
\widehat{U}_{1}^{S}(t, W, V)=\sup _{\pi \in \mathcal{A}_{a d}} \mathbb{E}\left[\hat{u}_{1}^{S}+\hat{v}_{1}^{S}+\hat{w}_{1}^{S} \mid W=W_{t}^{S}, V=V_{t}, \Theta_{t} \leq \ell_{1} V_{t}\right],
$$

where:

$$
\begin{gathered}
\hat{u}_{1}^{S}=-\exp \left(-\gamma W_{T}^{S}\right) 1_{\left\{\min \left\{\tau_{D}, \tau_{1}\right\} \geq T\right\}}, \\
\hat{v}_{1}^{S}=-\exp \left(-\gamma\left(e^{r\left(T-\tau_{D}\right)} W_{\tau_{D}}^{S}\right)\right) 1_{\left\{\tau_{D} \leq \min \left\{\tau_{1}, T\right\}\right\}}
\end{gathered}
$$




$$
\hat{w}_{1}^{S}=\widehat{U}_{2}^{S}\left(\tau_{1}, W_{\tau_{1}}^{S}, V_{\tau_{1}}\right) 1_{\left\{\tau_{1} \leq \min \left\{\tau_{D}, T\right\}\right\}}
$$

and:

$$
\widehat{U}_{i}^{S}(t, W, V)=\sup _{\pi \in \mathcal{A}_{a d}} \mathbb{E}\left[\hat{u}_{i}^{S}+\hat{v}_{i}^{S}+\hat{w}_{i}^{S} \mid W=W_{t}^{S}, V=V_{t}, \ell_{i-1} V_{t} \leq \Theta_{t} \leq \ell_{i} V_{t}\right]
$$

where:

$$
\begin{gathered}
\hat{u}_{i}^{S}=-\exp \left(-\gamma W_{T}^{S}\right) 1_{\left\{\min \left\{\tau_{D}, \tau_{i}\right\} \geq T\right\}}, \\
\hat{v}_{i}^{S}=-\exp \left(-\gamma\left(e^{r\left(T-\tau_{D}\right)} W_{\tau_{D}}^{S}\right) 1_{\left\{\tau_{D} \leq \min \left\{\tau_{i}, T\right\}\right\}},\right. \\
\hat{w}_{i}^{S}=\left(\widehat{U}_{i+1}^{S}\left(\tau_{i}, W_{\tau_{i}}^{S}, V_{\tau_{i}}\right) 1_{\left\{\Theta_{\tau_{i}} \geq \ell_{i} V_{\tau_{i}}\right\}}+\widehat{U}_{i-1}^{S}\left(\tau_{i}, W_{\tau_{i}}^{S}, V_{\tau_{i}}\right) 1_{\left\{\Theta_{\tau_{i}} \leq \ell_{i-1} V_{\tau_{i}}\right\}}\right) 1_{\left\{\tau_{i} \leq \min \left\{\tau_{D}, T\right\}\right\}},
\end{gathered}
$$

for $i=2,3, \cdots, n-1$, and:

$$
\widehat{U}_{n}^{S}(t, W, V)=\sup _{\pi \in \mathcal{A}_{a d}} \mathbb{E}\left[\hat{u}_{n}^{S}+\hat{v}_{n}^{S}+\hat{w}_{n}^{S} \mid W=W_{t}^{S}, V=V_{t}, \Theta_{t} \geq \ell_{n-1} V_{t}\right],
$$

where:

$$
\begin{gathered}
\hat{u}_{n}^{S}=-\exp \left(-\gamma W_{T}^{S}\right) 1_{\left\{\min \left\{\tau_{D}, \tau_{n}\right\} \geq T\right\}}, \\
\hat{v}_{n}^{S}=-\exp \left(-\gamma\left(e^{r\left(T-\tau_{D}\right)} W_{\tau_{D}}^{S}\right)\right) 1_{\left\{\tau_{D} \leq \min \left\{\tau_{n}, T\right\}\right\}}, \\
\hat{w}_{n}^{S}=\widehat{U}_{n-1}^{S}\left(\tau_{n}, W_{\tau_{n}}^{S}, V_{\tau_{n}}\right) 1_{\left\{\tau_{n} \leq \min \left\{\tau_{D}, T\right\}\right\}} .
\end{gathered}
$$

If the bond holder hedges the credit risk of the corporate bond by trading the stock, the indifference price of the corporate bond $\Theta_{t}$ is such that the value functions coincide, i.e.,

$$
U_{i}^{S}\left(t, W_{t}^{S}-\Theta_{t}, V_{t}\right)=\widehat{U}_{i}^{S}\left(t, W_{t}^{S}, V_{t}\right), i=1,2, \cdots, n .
$$

The second case is that the investor invests in the financial index $P$. Suppose that the investor holds the corporate bond, i.e., he/she hedges the credit risk of the corporate bond by trading the financial index $P$. The difference from investing in the stock is that after default, the investor can continue to trade the financial index, but with a shifted initial wealth depending on his/her loss from the default. The investor buys the corporate bond with the price $\Theta_{t}$ and invests in the financial index with the remaining wealth $W_{t}^{P}-\Theta_{t}$ at time $t$. If the firm defaults before credit rating migration during the time period $[t, T]$, i.e., on the set $\left\{\tau_{D} \leq \min \left\{\tau_{i}, T\right\}\right\}$ for some $1 \leq i \leq n$, meaning that firm is in the $i^{\prime}$ th credit rating at time $t$, the investor gets $W_{\tau_{D}}^{P}+H_{\tau_{D}}$ at the default time $\tau_{D}$. After the default, he/she continues to trade the financial index on the market, but with the shifted initial wealth $W_{\tau_{D}}^{P}+H_{\tau_{D}}$, and maximizes the utility:

$$
U_{0}^{P}\left(\tau_{D}, W_{\tau_{D}}^{P}+H_{\tau_{D}}\right)=\sup _{\pi} \mathbb{E}\left[-\exp \left(-\gamma \widehat{W}_{T}^{P}\right) \mid \widehat{W}_{\tau_{D}}^{P}=W_{\tau_{D}}^{P}+H_{\tau_{D}}\right]
$$

where $\widehat{W}^{P}$ still follows the wealth process (2), but with the shifted initial wealth $\widehat{W}_{\tau_{D}}^{P}=W_{\tau_{D}}^{P}+H_{\tau_{D}}$. Then, (4) is the standard exponential utility maximization problem, whose solution is known as:

$$
U_{0}^{P}\left(\tau_{D}, W_{\tau_{D}}^{P}+H_{\tau_{D}}\right)=-\exp \left(-\gamma e^{r\left(T-\tau_{D}\right)}\left(W_{\tau_{D}}^{P}+H_{\tau_{D}}\right)-\frac{\left(\mu_{P}-r\right)^{2}}{2 \sigma_{P}^{2}}\left(T-\tau_{D}\right)\right)
$$

which is the value function after the default on the set $\left\{\tau_{D} \leq \min \left\{\tau_{i}, T\right\}\right\}$ for some $1 \leq i \leq n$. If the credit rating migrates before default during the time period $[t, T]$, a virtual substitute termination happens, i.e., the contract is virtually terminated and substituted by a new one with a new credit rating 
on the set $\left\{\tau_{i} \leq \min \left\{\tau_{D}, T\right\}\right\}$ for some $1 \leq i \leq n$. If both the default and credit rating migration do not happen before maturity, i.e., on the set $\left\{\min \left\{\tau_{D}, \tau_{i}\right\} \geq T\right\}$ for some $1 \leq i \leq n$, the investor gets $W_{T}^{P}+H_{T}$ at maturity. Overall, the investor will maximize his/her utility:

$$
U_{1}^{P}(t, W, V)=\sup _{\pi \in \mathcal{A}_{a d}} \mathbb{E}\left[u_{1}^{P}+v_{1}^{P}+w_{1}^{P} \mid W=W_{t}^{S}-\Theta_{t}, V=V_{t}, \Theta_{t} \leq \ell_{1} V_{t}\right],
$$

where:

$$
\begin{gathered}
u_{1}^{P}=-\exp \left(-\gamma\left(W_{T}^{P}+H_{T}\right)\right) 1_{\left\{\min \left\{\tau_{D}, \tau_{1}\right\} \geq T\right\}}, \\
v_{1}^{P}=U_{0}^{P}\left(\tau_{D}, W_{\tau_{D}}^{P}+H_{\tau_{D}}\right) 1_{\left\{\tau_{D} \leq \min \left\{\tau_{1}, T\right\}\right\}}, \\
w_{1}^{P}=U_{2}^{P}\left(\tau_{1}, W_{\tau_{1}}^{P}, V_{\tau_{1}}\right) 1_{\left\{\tau_{1} \leq \min \left\{\tau_{D}, T\right\}\right\}}
\end{gathered}
$$

and:

$$
U_{i}^{P}(t, W, V)=\sup _{\pi \in \mathcal{A}_{a d}} \mathbb{E}\left[u_{i}^{P}+v_{i}^{P}+w_{i}^{P} \mid W=W_{t}^{P}-\Theta_{t}, V=V_{t}, \ell_{i-1} V_{t} \leq \Theta_{t} \leq \ell_{i} V_{t}\right],
$$

where:

$$
\begin{gathered}
u_{i}^{P}=-\exp \left(-\gamma\left(W_{T}^{P}+H_{T}\right)\right) 1_{\left\{\min \left\{\tau_{D}, \tau_{i}\right\} \geq T\right\}}, \\
v_{i}^{P}=U_{0}^{P}\left(\tau_{D}, W_{\tau_{D}}^{P}+H_{\tau_{D}}\right) 1_{\left\{\tau_{D} \leq \min \left\{\tau_{i}, T\right\}\right\}}, \\
w_{i}^{P}=\left(U_{i+1}^{P}\left(\tau_{i}, W_{\tau_{i}}^{P}, V_{\tau_{i}}\right) 1_{\left\{\Theta_{\tau_{i}} \geq \ell_{i} V_{\tau_{i}}\right\}}+U_{i-1}^{P}\left(\tau_{i}, W_{\tau_{i}}^{P}, V_{\tau_{i}}\right) 1_{\left\{\Theta_{\tau_{i}} \leq \ell_{i-1} V_{\tau_{i}}\right\}}\right) 1_{\left\{\tau_{i} \leq \min \left\{\tau_{D}, T\right\}\right\}},
\end{gathered}
$$

for $i=2,3, \cdots, n-1$, and:

$$
U_{n}^{P}(t, W, V)=\sup _{\pi \in \mathcal{A}_{a d}} \mathbb{E}\left[u_{n}^{P}+v_{n}^{P}+w_{n}^{P} \mid W=W_{t}^{P}-\Theta_{t}, V=V_{t}, \Theta_{t} \geq \ell_{n-1} V_{t}\right],
$$

where:

$$
\begin{gathered}
u_{n}^{P}=-\exp \left(-\gamma\left(W_{T}^{P}+H_{T}\right)\right) 1_{\left\{\min \left\{\tau_{D}, \tau_{n}\right\} \geq T\right\}}, \\
v_{n}^{P}=U_{0}^{P}\left(\tau_{D}, W_{\tau_{D}}^{P}+H_{\tau_{D}}\right) 1_{\left\{\tau_{D} \leq \min \left\{\tau_{n}, T\right\}\right\}}, \\
w_{n}^{P}=U_{n-1}^{P}\left(\tau_{n}, W_{\tau_{n}}^{P}, V_{\tau_{n}}\right) 1_{\left\{\tau_{n} \leq \min \left\{\tau_{D}, T\right\}\right\}} .
\end{gathered}
$$

Suppose that the investor does not hold the corporate bond. In this situation, both the default risk and credit rating migration risk will not impact the trading strategy of the investor. The problem reduces to a standard exponential utility problem:

$$
\widehat{U}^{P}(t, W)=\sup _{\pi \in \mathcal{A}_{a d}} \mathbb{E}\left[-\exp \left(-\gamma\left(W_{T}^{P}\right)\right) \mid W=W_{t}^{P}\right],
$$

which can be solved explicitly as:

$$
\widehat{U}^{P}(t, W)=-\exp \left(-\gamma e^{r(T-t)} W-\frac{\left(\mu_{P}-r\right)^{2}}{2 \sigma_{P}^{2}}(T-t)\right) .
$$

If the bond holder hedges the credit risk of the corporate bond by trading the financial index, the indifference price of the corporate bond $\Theta_{t}$ is such that the value function coincides, i.e.,

$$
U_{i}^{P}\left(t, W_{t}^{P}-\Theta_{t}, V_{t}\right)=\widehat{U}^{P}\left(t, W_{t}^{P}\right), i=1,2, \cdots, n .
$$




\subsection{Pricing Characteristics by the HJB Equation System}

The HJB equations are derived to characterize the indifference price of the corporate bond $\Theta_{t}$. The dynamic programming principle is employed. Before starting the lemma, let us define the following operators:

$$
\mathscr{L}_{i}^{S}=\left(r W+\left(\mu_{S}-r\right) \pi\right) \partial_{W}+\mu_{V} V \partial_{V}+\frac{\sigma_{S i}^{2}}{2} \pi^{2} \partial_{W W}+\frac{\sigma_{V i}^{2}}{2} V^{2} \partial_{V V}+\rho_{V S} \sigma_{S i} \pi \sigma_{V i} V \partial_{W V}
$$

and:

$$
\mathscr{L}_{i}^{P}=\left(r W+\left(\mu_{P}-r\right) \pi\right) \partial_{W}+\mu_{V} V \partial_{V}+\frac{\sigma_{P}^{2}}{2} \pi^{2} \partial_{W W}+\frac{\sigma_{V i}^{2}}{2} V^{2} \partial_{V V}+\rho_{V P} \sigma_{P} \pi \sigma_{V i} V \partial_{W V}
$$

for $i=1,2, \cdots, n$.

Lemma 1. The value functions $\left(U_{i}^{S}, i=1,2, \cdots, n\right)$ are the viscosity solutions of the following $H J B$ equation system:

$$
\left(U_{1}^{S}\right)_{t}+\sup _{\pi \in \mathcal{A}_{a d}} \mathscr{L}_{1}^{S} U_{1}^{S}=0, V \geq \ell_{1}^{-1} \Theta_{t}
$$

and:

$$
\left(U_{i}^{S}\right)_{t}+\sup _{\pi \in \mathcal{A}_{\text {ad }}} \mathscr{L}_{i}^{S} U_{i}^{S}=0, \ell_{i}^{-1} \Theta_{t} \leq V \leq \ell_{i-1}^{-1} \Theta_{t},
$$

for $i=2,3, \cdots, n-1$, and:

$$
\left(U_{n}^{S}\right)_{t}+\sup _{\pi \in \mathcal{A}_{a d}} \mathscr{L}_{n}^{S} U_{n}^{S}=0, D_{t} \leq V \leq \ell_{n-1}^{-1} \Theta_{t}
$$

with default boundary:

$$
\left.U_{n}^{S}(t, W, V)\right|_{V=D_{t}}=-\exp \left(-\gamma e^{r(T-t)}\left(W+\omega D_{t}\right)\right)
$$

and terminal condition:

$$
U_{i}^{S}(T, W, V)=-\exp (-\gamma(W+F)), i=1,2, \cdots, n .
$$

In addition, on the credit rating migration boundaries, it holds that:

$$
U_{i}^{S}(t, W, V)=U_{i+1}^{S}(t, W, V), i=1,2, \cdots, n-1 .
$$

The value functions $\left(\widehat{U}_{i}^{S}, i=1,2, \cdots, n\right)$ are the viscosity solutions of the following HJB equation system:

$$
\left(\widehat{U}_{1}^{S}\right)_{t}+\sup _{\pi \in \mathcal{A}_{a d}} \mathscr{L}_{1}^{S} \widehat{U}_{1}^{S}=0, V \geq \ell_{1}^{-1} \Theta_{t},
$$

and:

$$
\left(\widehat{U}_{i}^{S}\right)_{t}+\sup _{\pi \in \mathcal{A}_{a d}} \mathscr{L}_{i}^{S} \widehat{U}_{i}^{S}=0, \ell_{i}^{-1} \Theta_{t} \leq V \leq \ell_{i-1}^{-1} \Theta_{t},
$$

for $i=2,3, \cdots, n-1$, and:

$$
\left(\widehat{U}_{n}^{S}\right)_{t}+\sup _{\pi \in \mathcal{A}_{a d}} \mathscr{L}_{n}^{S} \widehat{U}_{n}^{S}=0, D_{t} \leq V \leq \ell_{n-1}^{-1} \Theta_{t},
$$

with default boundary:

$$
\left.\widehat{U}_{n}^{S}(t, W, V)\right|_{V=D_{t}}=-\exp \left(-\gamma e^{r(T-t)} W\right),
$$


and terminal condition:

$$
\widehat{U}_{i}^{S}(T, W, V)=-\exp (-\gamma W), i=1,2, \cdots, n .
$$

In addition, on the credit rating migration boundaries, it holds that:

$$
\widehat{U}_{i}^{S}(t, W, V)=\widehat{U}_{i+1}^{S}(t, W, V), i=1,2, \cdots, n-1 .
$$

The value functions $\left(U_{i}^{P}, i=1,2, \cdots, n\right)$ are the viscosity solutions of the following HJB equation system:

$$
\left(U_{1}^{P}\right)_{t}+\sup _{\pi \in \mathcal{A}_{a d}} \mathscr{L}_{1}^{P} U_{1}^{P}=0, V \geq \ell_{1}^{-1} \Theta_{t}
$$

and:

$$
\left(U_{i}^{P}\right)_{t}+\sup _{\pi \in \mathcal{A}_{\text {ad }}} \mathscr{L}_{i}^{P} U_{i}^{P}=0, \ell_{i}^{-1} \Theta_{t} \leq V \leq \ell_{i-1}^{-1} \Theta_{t},
$$

for $i=2,3, \cdots, n-1$, and:

$$
\left(U_{n}^{P}\right)_{t}+\sup _{\pi \in \mathcal{A}_{a d}} \mathscr{L}_{n}^{P} U_{n}^{P}=0, D_{t} \leq V \leq \ell_{n-1}^{-1} \Theta_{t}
$$

with default boundary:

$$
\left.U_{n}^{P}(t, W, V)\right|_{V=D_{t}}=-\exp \left(-\gamma e^{r(T-t)}\left(W+\omega D_{t}\right)-\frac{\left(\mu_{P}-r\right)^{2}}{2 \sigma_{P}^{2}}(T-t)\right)
$$

and terminal condition:

$$
U_{i}^{P}(T, W, V)=-\exp (-\gamma(W+F)), i=1,2, \cdots, n .
$$

In addition, on the credit rating migration boundaries, it holds that:

$$
U_{i}^{P}(t, W, V)=U_{i+1}^{P}(t, W, V), i=1,2, \cdots, n-1 .
$$

The proof of Lemma 1 can be found in Appendix A.

\section{Indifference Pricing for the Corporate Bond}

In this section, we solve the HJB equation systems (6)-(19) by a unified approach and derive the indifference price of the corporate bond under both situations, i.e., hedging credit risk by investing the stock issued by the firm itself or investing the financial index in the market.

We take $\left(U_{i}^{S}, i=1,2, \cdots, n\right)$ for example. The others $\left(\widehat{U}_{i}^{S}, i=1,2, \cdots, n\right)$ and $\left(U_{i}^{P}, i=1,2, \cdots, n\right)$ are parallel to this. To solve the HJB equation system, note that the corresponding optimal feedback control:

$$
\begin{aligned}
\pi_{i}^{*} & =\arg \max _{\pi \in \mathbb{R}}\left\{\left(\mu_{S}-r\right) \pi\left(U_{i}^{S}\right)_{W}+\frac{\sigma_{S i}^{2}}{2} \pi^{2}\left(U_{i}^{S}\right)_{W W}+\rho_{V S} \sigma_{S i} \pi \sigma_{V i} V\left(U_{i}^{S}\right)_{W V}\right\} \\
& =-\frac{\rho_{V S} \sigma_{S i} \sigma_{V i} V\left(U_{i}^{S}\right)_{W V}+\left(\mu_{S}-r\right)\left(U_{i}^{S}\right)_{W}}{\sigma_{S i}^{2}\left(U_{i}^{S}\right)_{W W}},
\end{aligned}
$$


for $i=1,2, \cdots, n$. Substituting (24) into the HJB Equations (6)-(8), we obtain the following Monge-Ampère equations:

$$
\begin{aligned}
& \sigma_{S i}^{2}\left(U_{i}^{S}\right)_{t}\left(U_{i}^{S}\right)_{W W}+r \sigma_{S i}^{2} W\left(U_{i}^{S}\right)_{W}\left(U_{i}^{S}\right)_{W W}-\frac{1}{2}\left(\mu_{j}-r\right)^{2}\left(U_{i}^{S}\right)_{W}^{2} \\
& -\left(\mu_{S}-r\right) \rho_{V S} \sigma_{S i} \sigma_{V i} V\left(U_{i}^{S}\right)_{V W}\left(U_{i}^{S}\right)_{W}+\mu_{V} \sigma_{S i}^{2} V\left(U_{i}^{S}\right)_{V}\left(U_{i}^{S}\right)_{W W} \\
& +\frac{1}{2} \sigma_{V i}^{2} \sigma_{S i}^{2} V^{2}\left(U_{i}^{S}\right)_{V V}\left(U_{i}^{S}\right)_{W W}-\frac{1}{2} \rho_{V S}^{2} \sigma_{S i}^{2} \sigma_{V i}^{2} V^{2}\left(U_{i}^{S}\right)_{V W}^{2}=0,
\end{aligned}
$$

for $i=1,2, \cdots, n$. By defining the new coordinates:

$$
x=W e^{r(T-t)}, y=V e^{\alpha(T-t)},
$$

then (25) reduces to:

$$
\begin{aligned}
& \sigma_{S i}^{2}\left(U_{i}^{S}\right)_{t}\left(U_{i}^{S}\right)_{x x}+\frac{1}{2} \sigma_{V i}^{2} \sigma_{S i}^{2} y^{2}\left(U_{i}^{S}\right)_{y y}\left(U_{i}^{S}\right)_{x x}-\frac{1}{2} \rho_{V S}^{2} \sigma_{S i}^{2} \sigma_{V i}^{2} y^{2}\left(U_{i}^{S}\right)_{x y}^{2} \\
& -\frac{1}{2}\left(\mu_{S}-r\right)^{2}\left(U_{i}^{S}\right)_{x}^{2}-\left(\mu_{S}-r\right) \rho_{V S} \sigma_{S i} \sigma_{V i} y\left(U_{i}^{S}\right)_{x y}\left(U_{i}^{S}\right)_{x} \\
& +\left(\mu_{V}-\alpha\right) \sigma_{S i}^{2} y\left(U_{i}^{S}\right)_{y}\left(U_{i}^{S}\right)_{x x}=0,
\end{aligned}
$$

for $i=1,2, \cdots, n$. Suppose that the solution of (26) has the following form:

$$
U_{i}^{S}(t, x, y)=-\exp \left(-\gamma\left(x+G_{i}^{S}(t, y)\right)\right), i=1,2, \cdots, n .
$$

It is easy to verify that $\left(G_{i}^{S}(t, y), i=1,2, \cdots, n\right)$ satisfy the following semi-linear PDEs with quadratic gradient:

$$
\begin{aligned}
& \sigma_{S i}^{2} \gamma\left(G_{i}^{S}\right)_{t}+\frac{1}{2} \gamma \sigma_{S i}^{2} \sigma_{V i}^{2} y^{2}\left(G_{i}^{S}\right)_{y y}+\frac{1}{2} \gamma^{2} \rho_{V S}^{2} \sigma_{S i}^{2} \sigma_{V i}^{2} y^{2}\left(G_{i}^{S}\right)_{y}^{2}-\frac{1}{2} \gamma^{2} \sigma_{V i}^{2} \sigma_{S i}^{2} y^{2}\left(G_{i}^{S}\right)_{y}^{2} \\
& +\left(\mu_{V}-\alpha\right) \gamma \sigma_{S i}^{2} y\left(G_{i}^{S}\right)_{y}-\left(\mu_{S}-r\right) \gamma \rho_{V S} \sigma_{S i} \sigma_{V i} y\left(G_{i}^{S}\right)_{y}+\frac{1}{2}\left(\mu_{S}-r\right)^{2}=0
\end{aligned}
$$

for $i=1,2, \cdots, n$. Then, we take the Cole-Hopf transformation, which is a well-known technique to deal with the above semi-linear PDEs with the quadratic gradient,

$$
G_{i}^{S}(t, y)=\frac{1}{\gamma \rho_{V S}^{2}-\gamma} \log H_{i}^{S}(t, y), i=1,2, \cdots, n .
$$

Then, under the transformation, $H_{i}^{S}(t, y)$ satisfies the following linear parabolic equations:

$$
\left(H_{i}^{S}\right)_{t}+\frac{\sigma_{V i}^{2}}{2} y^{2}\left(H_{i}^{S}\right)_{y y}+a_{S i} y\left(H_{i}^{S}\right)_{y}+b_{S i} H_{i}^{S}=0,
$$

where:

$$
\begin{gathered}
a_{S i}=\mu_{V}-\alpha-\frac{\left(\mu_{S}-r\right)}{\sigma_{S i}} \rho_{V S} \sigma_{V i}, \\
b_{S i}=\frac{1}{2 \sigma_{S i}^{2}}\left(\mu_{S}-r\right)^{2}\left(\rho_{V S}^{2}-1\right),
\end{gathered}
$$

for $i=1,2, \cdots, n$. Thus, we have the following lemma. 
Lemma 2. The HJB equation system (6)-(11) can be transformed into the following semi-linear parabolic equation system:

$$
\left(H_{1}^{S}\right)_{t}+\frac{\sigma_{V 1}^{2}}{2} y^{2}\left(H_{1}^{S}\right)_{y y}+a_{S 1} y\left(H_{1}^{S}\right)_{y}+b_{S 1} H_{1}^{S}=0, y \geq e^{\alpha(T-t)} \ell_{1}^{-1} \Theta
$$

and:

$$
\left(H_{i}^{S}\right)_{t}+\frac{\sigma_{V i}^{2}}{2} y^{2}\left(H_{i}^{S}\right)_{y y}+a_{S i} y\left(H_{i}^{S}\right)_{y}+b_{S i} H_{i}^{S}=0, e^{\alpha(T-t)} \ell_{i}^{-1} \Theta \leq y \leq e^{\alpha(T-t)} \ell_{i-1}^{-1} \Theta,
$$

for $i=2,3, \cdots, n-1$, and:

$$
\left(H_{n}^{S}\right)_{t}+\frac{\sigma_{V n}^{2}}{2} y^{2}\left(H_{n}^{S}\right)_{y y}+a_{S n} y\left(H_{n}^{S}\right)_{y}+b_{S n} H_{n}^{S}=0, D \leq y \leq e^{\alpha(T-t)} \ell_{n-1}^{-1} \Theta,
$$

with default boundary:

$$
H_{n}^{S}(t, D)=\exp \left(\gamma\left(\rho_{V S}^{2}-1\right) \omega D e^{(r-\alpha)(T-t)}\right)
$$

and terminal condition:

$$
H_{i}^{S}(T, y)=\exp \left(\gamma\left(\rho_{V S}^{2}-1\right) F\right), i=1,2, \cdots, n .
$$

In addition, on the credit rating migration boundaries, it holds that:

$$
H_{i}^{S}(t, y)=H_{i+1}^{S}(t, y), i=1,2, \cdots, n-1 .
$$

The HJB equation system (12)-(17) can be transformed into the following semi-linear parabolic equation system:

$$
\left(\widehat{H}_{1}^{S}\right)_{t}+\frac{\sigma_{V 1}^{2}}{2} y^{2}\left(\widehat{H}_{1}^{S}\right)_{y y}+a_{S 1} y\left(\widehat{H}_{1}^{S}\right)_{y}+b_{S 1} \widehat{H}_{1}^{S}=0, y \geq e^{\alpha(T-t)} \ell_{1}^{-1} \Theta
$$

and:

$$
\left(\widehat{H}_{i}^{S}\right)_{t}+\frac{\sigma_{V i}^{2}}{2} y^{2}\left(\widehat{H}_{i}^{S}\right)_{y y}+a_{S i} y\left(\widehat{H}_{i}^{S}\right)_{y}+b_{S i} \widehat{H}_{i}^{S}=0, e^{\alpha(T-t)} \ell_{i}^{-1} \Theta \leq y \leq e^{\alpha(T-t)} \ell_{i-1}^{-1} \Theta,
$$

for $i=2,3, \cdots, n-1$, and:

$$
\left(\widehat{H}_{n}^{S}\right)_{t}+\frac{\sigma_{V n}^{2}}{2} y^{2}\left(\widehat{H}_{n}^{S}\right)_{y y}+a_{S n} y\left(\widehat{H}_{n}^{S}\right)_{y}+b_{S n} \widehat{H}_{n}^{S}=0, D \leq y \leq e^{\alpha(T-t)} \ell_{n-1}^{-1} \Theta,
$$

with default boundary:

$$
\widehat{H}_{n}^{S}(t, D)=1,
$$

and terminal condition:

$$
\widehat{H}_{i}^{S}(T, y)=1, i=1,2, \cdots, n .
$$

In addition, on the credit rating migration boundaries, it holds that:

$$
\widehat{H}_{i}^{S}(t, y)=\widehat{H}_{i+1}^{S}(t, y), i=1,2, \cdots, n-1 .
$$

The HJB equation system (18)-(23) can be transformed into the following semi-linear parabolic equation system:

$$
\left(H_{1}^{P}\right)_{t}+\frac{\sigma_{V 1}^{2}}{2} y^{2}\left(H_{1}^{P}\right)_{y y}+a_{P 1} y\left(H_{1}^{P}\right)_{y}+b_{P 1} H_{1}^{P}=0, y \geq e^{\alpha(T-t)} \ell_{1}^{-1} \Theta,
$$

and:

$$
\left(H_{i}^{P}\right)_{t}+\frac{\sigma_{V i}^{2}}{2} y^{2}\left(H_{i}^{P}\right)_{y y}+a_{P i} y\left(H_{i}^{P}\right)_{y}+b_{P i} H_{i}^{P}=0, e^{\alpha(T-t)} \ell_{i}^{-1} \Theta \leq y \leq e^{\alpha(T-t)} \ell_{i-1}^{-1} \Theta
$$


for $i=2,3, \cdots, n-1$, and:

$$
\left(H_{n}^{P}\right)_{t}+\frac{\sigma_{V n}^{2}}{2} y^{2}\left(H_{n}^{P}\right)_{y y}+a_{P n} y\left(H_{n}^{P}\right)_{y}+b_{P n} H_{n}^{P}=0, D \leq y \leq e^{\alpha(T-t)} \ell_{n-1}^{-1} \Theta,
$$

with default boundary:

$$
H_{n}^{P}(t, D)=\exp \left(\gamma\left(\rho_{V P}^{2}-1\right)\left(e^{(r-\alpha)(T-t)} \omega D+\frac{\left(\mu_{P}-r\right)^{2}}{2 \gamma \sigma_{P}^{2}}(T-t)\right)\right),
$$

and terminal condition:

$$
H_{i}^{P}(T, y)=\exp \left(\gamma\left(\rho_{V P}^{2}-1\right) F\right), i=1,2, \cdots, n .
$$

In addition, on the credit rating migration boundaries, it holds that:

$$
H_{i}^{P}(t, y)=H_{i+1}^{P}(t, y), i=1,2, \cdots, n-1 .
$$

Now, we would like to solve system (27)-(44) and present explicit formulas for their solutions. We take System (27)-(32) for example. System (33)-(44) is parallel to this.

Take $y=e^{z}$ and the remaining $T-t$ as $t$; System (27)-(32) is transformed into:

$$
\left(H_{1}^{S}\right)_{t}-\frac{\sigma_{V 1}^{2}}{2}\left(H_{1}^{S}\right)_{z z}-\left(a_{S 1}-\frac{\sigma_{V 1}^{2}}{2}\right)\left(H_{1}^{S}\right)_{z}-b_{S 1} H_{1}^{S}=0,
$$

for $z \geq \alpha t-\log \ell_{1}+\log \Theta$,

$$
\left(H_{i}^{S}\right)_{t}-\frac{\sigma_{V i}^{2}}{2}\left(H_{i}^{S}\right)_{z z}-\left(a_{S i}-\frac{\sigma_{V i}^{2}}{2}\right)\left(H_{i}^{S}\right)_{z}-b_{S i} H_{i}^{S}=0,
$$

for $\alpha t-\log \ell_{i}+\log \Theta \leq z \leq \alpha t-\log \ell_{i-1}+\log \Theta, i=2,3, \cdots, n-1$, and:

$$
\left(H_{n}^{S}\right)_{t}-\frac{\sigma_{V n}^{2}}{2}\left(H_{n}^{S}\right)_{z z}-\left(a_{S n}-\frac{\sigma_{V n}^{2}}{2}\right)\left(H_{n}^{S}\right)_{z}-b_{S n} H_{n}^{S}=0,
$$

for $\log D \leq z \leq \alpha t-\log \ell_{n-1}+\log \Theta$, with default boundary:

$$
H_{n}^{S}(t, \log D)=\exp \left(\gamma\left(\rho_{V S}^{2}-1\right) \omega D e^{(r-\alpha) t}\right),
$$

and initial condition:

$$
H_{i}^{S}(0, z)=\exp \left(\gamma\left(\rho_{V S}^{2}-1\right) F\right), i=1,2, \cdots, n .
$$

Make the transformation:

$$
H_{i}^{S}(t, z)=e^{\kappa_{S i} t+\beta_{S i} z} N_{i}^{S}(t, z)
$$

where:

$$
\beta_{S i}=\frac{1}{2}-\frac{a_{S i}}{\sigma_{V i}^{2}}, \kappa_{S i}=\frac{\sigma_{V i}^{2}}{2} \beta_{S i}^{2}+\left(a_{S i}-\frac{\sigma_{V i}^{2}}{2}\right) \beta_{S i}+b_{S i},
$$

for $i=1,2, \cdots, n$. Then, $\left(N_{i}^{S}(t, z), i=1,2, \cdots, n\right)$ satisfy:

$$
\left(N_{1}^{S}\right)_{t}-\frac{\sigma_{V 1}^{2}}{2}\left(N_{1}^{S}\right)_{z z}=0,
$$

for $z \geq \alpha t-\log \ell_{1}+\log \Theta$,

$$
\left(N_{i}^{S}\right)_{t}-\frac{\sigma_{V i}^{2}}{2}\left(N_{i}^{S}\right)_{z z}=0,
$$


for $\alpha t-\log \ell_{i}+\log \Theta \leq z \leq \alpha t-\log \ell_{i-1}+\log \Theta, i=2,3, \cdots, n-1$, and:

$$
\left(N_{n}^{S}\right)_{t}-\frac{\sigma_{V n}^{2}}{2}\left(N_{n}^{S}\right)_{z z}=0
$$

for $\log D \leq z \leq \alpha t-\log \ell_{n-1}+\log \Theta$, with default boundary:

$$
N_{n}^{S}(t, \log D)=\exp \left(\gamma\left(\rho_{V S}^{2}-1\right) \omega D e^{(r-\alpha) t}-\kappa_{n}^{S} t-\beta_{n}^{S} \log D\right),
$$

and initial condition:

$$
N_{i}^{S}(0, z)=\exp \left(\gamma\left(\rho_{V S}^{2}-1\right) F-\beta_{i}^{S} z\right), i=1,2, \cdots, n .
$$

The solutions $\left(N_{i}^{S}(t, z), i=1,2, \cdots, n\right)$ will be solved by an inverted iteration, i.e., we solve $N_{n}^{S}(t, z)$ first of all, which satisfies:

$$
\left(N_{n}^{S}\right)_{t}-\frac{\sigma_{V n}^{2}}{2}\left(N_{n}^{S}\right)_{z z}=0, \log D \leq z \leq \alpha t-\log \ell_{n-1}+\log \Theta,
$$

with boundary condition:

$$
N_{n}^{S}(t, \log D)=\exp \left(\gamma\left(\rho_{V S}^{2}-1\right) \omega D e^{(r-\alpha) t}-\kappa_{S n} t-\beta_{S n} \log D\right),
$$

and initial condition:

$$
N_{n}^{S}(0, z)=\exp \left(\gamma\left(\rho_{V S}^{2}-1\right) F-\beta_{S n} z\right) .
$$

Taking a shift $\zeta=z-\log D$, then System (46)-(48) turns into:

$$
\left(N_{n}^{S}\right)_{t}-\frac{\sigma_{V n}^{2}}{2}\left(N_{n}^{S}\right)_{\zeta \zeta}=0,0 \leq \zeta \leq \alpha t-\log \ell_{n-1}+\log \Theta-\log D,
$$

with boundary condition:

$$
N_{n}^{S}(t, 0)=\phi_{n}^{S}(t):=\exp \left(\gamma\left(\rho_{V S}^{2}-1\right) \omega D e^{(r-\alpha) t}-\kappa_{S n} t-\beta_{S n} \log D\right),
$$

and initial condition:

$$
N_{n}^{S}(0, \zeta)=\exp \left(\gamma\left(\rho_{V S}^{2}-1\right) F-\beta_{S n} \zeta-\beta_{S n} \log D\right) .
$$

Let $N_{n}^{S}(t, \zeta)=M_{n}^{S}(t, \zeta)+\phi_{n}^{S}(t)$. Then, $M_{n}^{S}(t, \zeta)$ satisfies:

$$
\left(M_{n}^{S}\right)_{t}-\frac{\sigma_{V n}^{2}}{2}\left(M_{n}^{S}\right)_{\zeta \zeta}=-\left(\phi_{n}^{S}\right)^{\prime}, 0 \leq \zeta \leq \alpha t-\log \ell_{n-1}+\log \Theta-\log D,
$$

with boundary condition $M_{n}^{S}(t, 0)=0$ and initial condition:

$$
M_{n}^{S}(0, \zeta)=\varphi_{n}^{S}(\zeta):=\exp \left(\gamma\left(\rho_{V S}^{2}-1\right) F-\beta_{S n} \zeta-\beta_{S n} \log D\right)-\phi_{n}^{S}(0) .
$$

We do not regard the boundary $\alpha t-\log \ell_{n-1}+\log \Theta-\log D$ provisionally. By the image method, the system (49) and (50) turns into:

$$
\left(M_{n}^{S}\right)_{t}-\frac{\sigma_{V n}^{2}}{2}\left(M_{n}^{S}\right)_{\zeta \zeta}=A_{n}(t, \zeta),-\infty \leq \zeta \leq \infty,
$$

where:

$$
A_{n}(t, \zeta)=-\left(\phi_{n}^{S}\right)^{\prime}(t) \text { for } 0<\zeta<\infty, A_{n}(t, \zeta)=\left(\phi_{n}^{S}\right)^{\prime}(t) \text { for }-\infty<\zeta<0
$$


with initial condition $M_{n}^{S}(0, \zeta)=B_{n}(\zeta)$ satisfying:

$$
B_{n}(\zeta)=\varphi_{n}^{S}(\zeta) \text { for } 0<\zeta<\infty, B_{n}(\zeta)=-\varphi_{n}^{S}(-\zeta) \text { for }-\infty<\zeta<0 .
$$

Then, let $M_{n}^{S}(t, \zeta)=R_{n}^{S}(t, \zeta)+Q_{n}^{S}(t, \zeta)$, where $R_{n}^{S}(t, \zeta)$ satisfies:

$$
\left(R_{n}^{S}\right)_{t}-\frac{\sigma_{V n}^{2}}{2}\left(R_{n}^{S}\right)_{\zeta \zeta}=A_{n}(t, \zeta),-\infty \leq \zeta \leq \infty,
$$

with initial condition $R_{n}^{S}(0, \zeta)=0$, and $Q_{n}^{S}(t, \zeta)$ satisfies:

$$
\left(Q_{n}^{S}\right)_{t}-\frac{\sigma_{V n}^{2}}{2}\left(Q_{n}^{S}\right)_{\zeta \zeta}=0,-\infty \leq \zeta \leq \infty,
$$

with initial condition $Q_{n}^{S}(0, \zeta)=B_{n}(\zeta)$. By the classical methodology, we can solve $R_{n}^{S}(t, \zeta)$ as:

$$
R_{n}^{S}(t, \zeta)=\int_{0}^{t}\left(\phi_{n}^{S}\right)^{\prime}(s)\left(\frac{2}{\sqrt{2 \pi}} \int_{-\infty}^{-\zeta / \sigma_{V n} \sqrt{t-s}} \exp \left(-\frac{y^{2}}{2}\right) d y-1\right) d s,
$$

and $Q_{n}^{S}(t, \zeta)$ as:

$$
Q_{n}^{S}(t, \zeta)=\frac{1}{\sigma_{V n} \sqrt{2 \pi t}} \int_{0}^{\infty}\left(\exp \left(-\frac{(\zeta-\xi)^{2}}{2 \sigma_{V n}^{2} t}\right)-\exp \left(-\frac{(\zeta+\xi)^{2}}{2 \sigma_{V n}^{2} t}\right)\right) \varphi_{n}^{S}(\xi) d \xi
$$

Thus, $N_{n}^{S}(t, z)$ satisfies:

$$
N_{n}^{S}(t, z)=R_{n}^{S}(t, z-\log D)+Q_{n}^{S}(t, z-\log D)+\phi_{n}^{S}(t),
$$

on the credit region $0 \leq z \leq \alpha t-\log \ell_{n-1}+\log \Theta$. Then, with (51), we start to solve the following problem on the sub-lowest credit rating region:

$$
\left(N_{n-1}^{S}\right)_{t}-\frac{\sigma_{V n-1}^{2}}{2}\left(N_{n-1}^{S}\right)_{z z}=0,
$$

with boundary condition (by (32)):

$$
\left.N_{n-1}^{S}(t, z)\right|_{z=\phi_{n-1}^{S}(t)}=N_{n}^{S}\left(t, \phi_{n-1}^{S}(t)\right),
$$

where:

$$
\psi_{n-1}(t)=\alpha t-\log \ell_{n-1}+\log \Theta,
$$

and initial condition:

$$
N_{n-1}^{S}(0, z)=\exp \left(\gamma\left(\rho_{V S}^{2}-1\right) F-\beta_{S n-1} z\right) .
$$

Take a transformation of coordinates:

$$
z=\psi_{n-1}(t) \zeta+\psi_{n-1}(t) .
$$

Then, $N_{n-1}^{S}(t, \zeta)$ satisfies:

$$
\left(N_{n-1}^{S}\right)_{t}-\frac{\psi_{n-1}^{\prime}}{\psi_{n-1}} \zeta\left(N_{n-1}^{S}\right)_{\zeta}-\frac{\sigma_{V n-1}^{2}}{2 \psi_{n-1}^{2}}\left(N_{n-1}^{S}\right)_{\zeta \zeta}=0,
$$

with boundary condition:

$$
N_{n-1}^{S}(t, 0)=N_{n}^{S}\left(t, \psi_{n-1}(t)\right)
$$


and initial condition:

$$
N_{n-1}^{S}(0, \zeta)=\exp \left(\gamma\left(\rho_{V S}^{2}-1\right) F-\beta_{S n-1}\left(\log F-\log \ell_{n-1}\right)(\zeta+1)\right) .
$$

Let $N_{n-1}^{S}(t, \zeta)=M_{n-1}^{S}(t, \zeta)+N_{n}^{S}\left(t, \psi_{n-1}(t)\right)$. Then, $M_{n-1}^{S}(t, \zeta)$ satisfies:

$$
\left(M_{n-1}^{S}\right)_{t}-\frac{\psi_{n-1}^{\prime}}{\psi_{n-1}} \zeta\left(M_{n-1}^{S}\right)_{\zeta}-\frac{\sigma_{V n-1}^{2}}{2 \psi_{n-1}^{2}}\left(M_{n-1}^{S}\right)_{\zeta \zeta}=-\left(N_{n}^{S}\left(t, \psi_{n-1}(t)\right)\right)^{\prime},
$$

with boundary condition $M_{n-1}^{S}(t, 0)=0$ and initial condition $M_{n-1}^{S}(0, \zeta)=\varphi_{n-1}^{S}(\zeta)$, where:

$$
\varphi_{n-1}^{S}(\zeta)=\exp \left(\gamma\left(\rho_{V S}^{2}-1\right) F-\beta_{S n-1}\left(\log F-\log \ell_{n-1}\right)(\zeta+1)\right)-N_{n}^{S}\left(0, \psi_{n-1}(0)\right) .
$$

Similarly, by the image method, we extend the domain $[0, \infty)$ to $(-\infty, \infty)$. (52) turns into:

$$
\left(M_{n-1}^{S}\right)_{t}-\frac{\psi_{n-1}^{\prime}}{\psi_{n-1}} \zeta\left(M_{n-1}^{S}\right)_{\zeta}-\frac{\sigma_{V n-1}^{2}}{2 \psi_{n-1}^{2}}\left(M_{n-1}^{S}\right)_{\zeta \zeta}=A_{n-1}(t, \zeta),-\infty<\zeta<\infty,
$$

where:

$$
A_{n-1}=-\left(N_{n}^{S}\left(t, \psi_{n-1}(t)\right)\right)^{\prime} \text { for } 0<\zeta<\infty, A_{n-1}=\left(N_{n}^{S}\left(t, \psi_{n-1}(t)\right)\right)^{\prime} \text { for }-\infty<\zeta<0,
$$

with initial condition $M_{n-1}^{S}(0, \zeta)=B_{n-1}(\zeta)$ satisfying:

$$
B_{n-1}(\zeta)=\varphi_{n-1}^{S}(\zeta) \text { for } 0<\zeta<\infty, B_{n-1}(\zeta)=-\varphi_{n-1}^{S}(-\zeta) \text { for }-\infty<\zeta<0 .
$$

Let $M_{n-1}^{S}(t, \zeta)=R_{n-1}^{S}(t, \zeta)+Q_{n-1}^{S}(t, \zeta)$, where $R_{n-1}^{S}(t, \zeta)$ satisfies:

$$
\left(R_{n-1}^{S}\right)_{t}-\frac{\psi_{n-1}^{\prime}}{\psi_{n-1}} \zeta\left(R_{n-1}^{S}\right)_{\zeta}-\frac{\sigma_{V n-1}^{2}}{2 \psi_{n-1}^{2}}\left(R_{n-1}^{S}\right)_{\zeta \zeta}=A_{n-1}(t, \zeta),-\infty<\zeta<\infty,
$$

with initial condition $R_{n-1}^{S}(0, \zeta)=0$, and $Q_{n-1}^{S}(t, \zeta)$ satisfies:

$$
\left(Q_{n-1}^{S}\right)_{t}-\frac{\psi_{n-1}^{\prime}}{\psi_{n-1}} \zeta\left(Q_{n-1}^{S}\right)_{\zeta}-\frac{\sigma_{V n-1}^{2}}{2 \psi_{n-1}^{2}}\left(Q_{n-1}^{S}\right)_{\zeta \zeta}=0,-\infty<\zeta<\infty,
$$

with initial condition $Q_{n-1}^{S}(0, \zeta)=B_{n-1}(\zeta)$. It is not difficult to verify that:

$$
R_{n-1}^{S}(t, \zeta)=\int_{0}^{t}\left(N_{n}^{S}\left(s, \psi_{n-1}(s)\right)\right)^{\prime}\left(\frac{2}{\sqrt{2 \pi}} \int_{-\infty}^{-\psi_{n-1}(t) \zeta / \sigma_{V n-1} \sqrt{t-s}} \exp \left(-\frac{y^{2}}{2}\right) d y-1\right) d s,
$$

and:

$$
Q_{n-1}^{S}(t, \zeta)=\frac{1}{\sigma_{V n-1} \sqrt{2 \pi t}} \int_{0}^{\infty}\left(\exp \left(-\frac{\left(\psi_{n-1} \zeta-\xi\right)^{2}}{2 \sigma_{V n-1}^{2} t}\right)-\exp \left(-\frac{\left(\psi_{n-1} \zeta+\xi\right)^{2}}{2 \sigma_{V n-1}^{2} t}\right)\right) \varphi_{n-1}^{S}(\xi) d \xi,
$$

which means that $N_{n-1}^{S}(t, z)$ satisfies:

$$
N_{n-1}^{S}(t, z)=R_{n-1}^{S}\left(t,\left(\psi_{n-1}\right)^{-1} z-1\right)+Q_{n-1}^{S}\left(t,\left(\psi_{n-1}\right)^{-1} z-1\right)+N_{n}^{S}\left(t, \psi_{n-1}(t)\right) .
$$

Repeating these procedures, we can derive the explicit formulas for all $N_{i}^{S}(t, z), i=1,2, \cdots, n-1$ in an inverted order. Hence, similarly, for system (33)-(38), we have:

$$
\widehat{H}_{n}^{S}(t, z)=\exp \left(\kappa_{S n} t+\beta_{S n} z\right) \widehat{N}_{n}^{S}(t, z),
$$


where:

$$
\begin{gathered}
\widehat{N}_{n}^{S}(t, z)=\widehat{R}_{n}^{S}(t, z-\log D)+\widehat{Q}_{n}^{S}(t, z-\log D)+\widehat{\phi}_{n}^{S}(t), \\
\widehat{\phi}_{n}^{S}(t)=\exp \left(-\kappa_{S n} t-\beta_{S n} \log D\right), \\
\widehat{\varphi}_{n}^{S}(\zeta)=\exp \left(-\beta_{S n} \zeta-\beta_{S n} \log D\right)-\widehat{\phi}_{n}^{S}(0), \\
\widehat{R}_{n}^{S}(t, \zeta)=\int_{0}^{t}\left(\widehat{\phi}_{n}^{S}\right)^{\prime}(s)\left(\frac{2}{\sqrt{2 \pi}} \int_{-\infty}^{-\zeta / \sigma_{V n} \sqrt{t-s}} \exp \left(-\frac{y^{2}}{2}\right) d y-1\right) d s,
\end{gathered}
$$

and:

$$
\widehat{Q}_{n}^{S}(t, \zeta)=\frac{1}{\sigma_{V n} \sqrt{2 \pi t}} \int_{0}^{\infty}\left(\exp \left(-\frac{(\zeta-\xi)^{2}}{2 \sigma_{V n}^{2} t}\right)-\exp \left(-\frac{(\zeta+\xi)^{2}}{2 \sigma_{V n}^{2} t}\right)\right) \widehat{\varphi}_{n}^{S}(\xi) d \xi,
$$

and:

$$
\widehat{H}_{i}^{S}(t, z)=\exp \left(\kappa_{S i} t+\beta_{S i} z\right) \widehat{N}_{i}^{S}(t, z)
$$

where:

$$
\begin{gathered}
\widehat{N}_{i}^{S}(t, z)=\widehat{R}_{i}^{S}\left(t,\left(\psi_{i}\right)^{-1} z-1\right)+\widehat{Q}_{i}^{S}\left(t,\left(\psi_{i}\right)^{-1} z-1\right)+\widehat{N}_{i+1}^{S}\left(t, \psi_{i}(t)\right), \\
\widehat{\varphi}_{i}^{S}(\zeta)=\exp \left(-\beta_{S i}\left(\log F-\log \ell_{i}\right)(\zeta+1)\right)-\widehat{N}_{i+1}^{S}\left(0, \psi_{i}(0)\right), \\
\widehat{R}_{i}^{S}(t, \zeta)=\int_{0}^{t}\left(\widehat{N}_{i+1}^{S}\left(s, \psi_{i}(s)\right)\right)^{\prime}\left(\frac{2}{\sqrt{2 \pi}} \int_{-\infty}^{-\psi_{i}(t) \zeta / \sigma_{V i} \sqrt{t-s}} \exp \left(-\frac{y^{2}}{2}\right) d y-1\right) d s,
\end{gathered}
$$

and:

$$
\widehat{Q}_{i}^{S}(t, \zeta)=\frac{1}{\sigma_{V i} \sqrt{2 \pi t}} \int_{0}^{\infty}\left(\exp \left(-\frac{\left(\psi_{i} \zeta-\xi\right)^{2}}{2 \sigma_{V i}^{2} t}\right)-\exp \left(-\frac{\left(\psi_{i} \zeta+\xi\right)^{2}}{2 \sigma_{V i}^{2} t}\right)\right) \widehat{\varphi}_{i}^{S}(\xi) d \xi,
$$

for $i=1,2, \cdots, n-1$. Denote by:

$$
\beta_{P i}=\frac{1}{2}-\frac{a_{P i}}{\sigma_{V i}^{2}}, \kappa_{P i}=\frac{\sigma_{V i}^{2}}{2} \beta_{P i}^{2}+\left(a_{P i}-\frac{\sigma_{V i}^{2}}{2}\right) \beta_{P i}+b_{P i}, i=1,2, \cdots, n .
$$

For System (39)-(44), we have:

$$
H_{n}^{P}(t, z)=\exp \left(\kappa_{P n} t+\beta_{P n} z\right) N_{n}^{P}(t, z),
$$

where:

$$
\begin{gathered}
N_{n}^{P}(t, z)=R_{n}^{P}(t, z-\log D)+Q_{n}^{P}(t, z-\log D)+\phi_{n}^{P}(t), \\
\phi_{n}^{P}(t)=\exp \left(\gamma\left(\rho_{V P}^{2}-1\right)\left(e^{(r-\alpha) t} \omega D+\frac{\left(\mu_{P}-r\right)^{2}}{2 \gamma \sigma_{P}^{2}} t\right)-\kappa_{P n} t-\beta_{P n} \log D\right), \\
\varphi_{n}^{P}(\zeta)=\exp \left(\gamma\left(\rho_{V P}^{2}-1\right) F-\beta_{P n} \zeta-\beta_{P n} \log D\right)-\phi_{n}^{P}(0), \\
R_{n}^{P}(t, \zeta)=\int_{0}^{t}\left(\phi_{n}^{P}\right)^{\prime}(s)\left(\frac{2}{\sqrt{2 \pi}} \int_{-\infty}^{-\zeta / \sigma_{V n} \sqrt{t-s}} \exp \left(-\frac{y^{2}}{2}\right) d y-1\right) d s,
\end{gathered}
$$

and:

$$
Q_{n}^{P}(t, \zeta)=\frac{1}{\sigma_{V n} \sqrt{2 \pi t}} \int_{0}^{\infty}\left(\exp \left(-\frac{(\zeta-\xi)^{2}}{2 \sigma_{V n}^{2} t}\right)-\exp \left(-\frac{(\zeta+\xi)^{2}}{2 \sigma_{V n}^{2} t}\right)\right) \varphi_{n}^{P}(\xi) d \xi
$$

and:

$$
H_{i}^{P}(t, z)=\exp \left(\kappa_{P i} t+\beta_{P i} z\right) N_{i}^{P}(t, z),
$$


where:

$$
\begin{gathered}
N_{i}^{P}(t, z)=R_{i}^{P}\left(t,\left(\psi_{i}\right)^{-1} z-1\right)+Q_{i}^{P}\left(t,\left(\psi_{i}\right)^{-1} z-1\right)+N_{i+1}^{P}\left(t, \psi_{i}(t)\right), \\
\varphi_{i}^{P}(\zeta)=\exp \left(\gamma\left(\rho_{V P}^{2}-1\right) F-\beta_{P i}\left(\log F-\log \ell_{i}\right)(\zeta+1)\right)-N_{i+1}^{P}\left(0, \psi_{i}(0)\right), \\
R_{i}^{P}(t, \zeta)=\int_{0}^{t}\left(N_{i+1}^{P}\left(s, \psi_{i}(s)\right)\right)^{\prime}\left(\frac{2}{\sqrt{2 \pi}} \int_{-\infty}^{-\psi_{i}(t) \zeta / \sigma_{V i} \sqrt{t-s}} \exp \left(-\frac{y^{2}}{2}\right) d y-1\right) d s,
\end{gathered}
$$

and:

$$
Q_{i}^{P}(t, \zeta)=\frac{1}{\sigma_{V i} \sqrt{2 \pi t}} \int_{0}^{\infty}\left(\exp \left(-\frac{\left(\psi_{i} \zeta-\xi\right)^{2}}{2 \sigma_{V i}^{2} t}\right)-\exp \left(-\frac{\left(\psi_{i} \zeta+\xi\right)^{2}}{2 \sigma_{V i}^{2} t}\right)\right) \varphi_{i}^{P}(\xi) d \xi,
$$

for $i=1,2, \cdots, n-1$. Accordingly, we have the following lemma.

Lemma 3. Denote by $\left(\psi_{i}(t, \Theta), i=1,2, \cdots, n-1\right)$ the credit rating boundaries:

$$
\psi_{i}(t, \Theta)=\alpha(T-t)-\log \ell_{i}+\log \Theta, i=1,2, \cdots, n-1 .
$$

Let $\left(H_{i}^{S}(t, y), i=1,2, \cdots, n\right)$ be the solutions of System (27)-(32). Then, they satisfy:

$$
H_{n}^{S}(t, y)=\exp \left(\kappa_{S n}(T-t)+\beta_{S n} \log y\right) N_{n}^{S}(T-t, \log y),
$$

for $D \leq y \leq \exp \left(\psi_{n-1}(t, \Theta)\right)$, where $N_{n}^{S}$ is given by (51),

$$
H_{n-1}^{S}\left(t, y ; \psi_{n-1}(t, \Theta)\right)=\exp \left(\kappa_{S n-1}(T-t)+\beta_{S n-1} \log y\right) N_{n-1}^{S}\left(T-t, \log y ; \psi_{n-1}(t, \Theta)\right),
$$

for $\exp \left(\psi_{n-1}(t, \Theta)\right) \leq y \leq \exp \left(\psi_{n-2}(t, \Theta)\right)$, where $N_{n-1}^{S}$ is given by (53), depending on $N_{n}^{S}$,

$$
H_{1}^{S}\left(t, y ; \psi_{1}(t, \Theta)\right)=\exp \left(\kappa_{S 1}(T-t)+\beta_{S 1} \log y\right) N_{1}^{S}\left(T-t, \log y ; \psi_{1}(t, \Theta)\right),
$$

for $y \geq \exp \left(\psi_{1}(t, \Theta)\right)$, where $N_{1}^{S}$ is also given by (53), depending on $N_{2}^{S}$. Let $\left(\widehat{H}_{i}^{S}(t, y), i=1,2, \cdots, n\right)$ be the solutions of system (33)-(38). Then, they satisfy:

$$
\widehat{H}_{n}^{S}(t, y)=\exp \left(\kappa_{S n}(T-t)+\beta_{S n} \log y\right) \widehat{N}_{n}^{S}(T-t, \log y),
$$

for $D \leq y \leq \exp \left(\psi_{n-1}(t, \Theta)\right)$, where $\widehat{N}_{n}^{S}$ is given by (54),

$$
\widehat{H}_{n-1}^{S}\left(t, y ; \psi_{n-1}(t, \Theta)\right)=\exp \left(\kappa_{S n-1}(T-t)+\beta_{S n-1} \log y\right) \widehat{N}_{n-1}^{S}\left(T-t, \log y ; \psi_{n-1}(t, \Theta)\right),
$$

for $\exp \left(\psi_{n-1}(t, \Theta)\right) \leq y \leq \exp \left(\psi_{n-2}(t, \Theta)\right)$, where $\widehat{N}_{n-1}^{S}$ is given by (55), depending on $\widehat{N}_{n}^{S}$,

$$
\widehat{H}_{1}^{S}\left(t, y ; \psi_{1}(t, \Theta)\right)=\exp \left(\kappa_{S 1}(T-t)+\beta_{S 1} \log y\right) \widehat{N}_{1}^{S}\left(T-t, \log y ; \psi_{1}(t, \Theta)\right),
$$

for $y \geq \exp \left(\psi_{1}(t, \Theta)\right)$, where $\widehat{N}_{1}^{S}$ is also given by (55), depending on $\widehat{N}_{2}^{S}$. Let $\left(H_{i}^{P}(t, y), i=1,2, \cdots, n\right)$ be the solutions of System (39)-(44). Then, they satisfy:

$$
H_{n}^{P}(t, y)=\exp \left(\kappa_{P n}(T-t)+\beta_{P n} \log y\right) N_{n}^{P}(T-t, \log y),
$$


for $D \leq y \leq \exp \left(\psi_{n-1}(t, \Theta)\right)$, where $N_{n}^{P}$ is given by (56),

$$
H_{n-1}^{P}\left(t, y ; \psi_{n-1}(t, \Theta)\right)=\exp \left(\kappa_{P n-1}(T-t)+\beta_{P n-1} \log y\right) N_{n-1}^{P}\left(T-t, \log y ; \psi_{n-1}(t, \Theta)\right),
$$

for $\exp \left(\psi_{n-1}(t, \Theta)\right) \leq y \leq \exp \left(\psi_{n-2}(t, \Theta)\right)$, where $N_{n-1}^{P}$ is given by (57), depending on $N_{n}^{P}$,

$$
H_{1}^{P}\left(t, y ; \psi_{1}(t, \Theta)\right)=\exp \left(\kappa_{P 1}(T-t)+\beta_{P 1} \log y\right) N_{1}^{P}\left(T-t, \log y ; \psi_{1}(t, \Theta)\right),
$$

for $y \geq \exp \left(\psi_{1}(t, \Theta)\right)$, where $N_{1}^{P}$ is also given by (57), depending on $N_{2}^{P}$.

Now, we are in the position of presenting the main theorem of the paper, which gives the explicit pricing formulas for the indifference price of the corporate bond.

Theorem 1. Denote by $\left(\psi_{i}(t, \Theta), i=1,2, \cdots, n-1\right)$ the credit rating boundaries:

$$
\psi_{i}(t, \Theta)=\alpha(T-t)-\log \ell_{i}+\log \Theta, i=1,2, \cdots, n-1 .
$$

Denote by $\Theta_{i}$ the price of the bond in the $i$ 'th credit rating of the firm, where $i=1,2, \cdots, n$. Suppose that the bond holder hedges the credit risk of the corporate bond by trading the stock. Then, the prices of the corporate bond $\left(\Theta_{i}, i=1,2, \cdots, n\right)$ satisfy:

$$
\Theta_{n}(t, V)=\frac{e^{-r(T-t)}}{\gamma\left(\rho_{V S}^{2}-1\right)} \log \frac{H_{n}^{S}\left(t, V e^{\alpha(T-t)}\right)}{\widehat{H}_{n}^{S}\left(t, V e^{\alpha(T-t)}\right)},
$$

for $D e^{-\alpha(T-t)} \leq V \leq \ell_{n-1}^{-1} \Theta_{n}(t, V)$,

$$
\Theta_{n-1}(t, V)=\frac{e^{-r(T-t)}}{\gamma\left(\rho_{V S}^{2}-1\right)} \log \frac{H_{n-1}^{S}\left(t, V e^{\alpha(T-t)} ; \psi_{n-1}\left(t, \Theta_{n}\right)\right)}{\widehat{H}_{n-1}^{S}\left(t, V e^{\alpha(T-t)}, \psi_{n-1}\left(t, \Theta_{n}\right)\right)},
$$

for $\ell_{n-1}^{-1} \Theta_{n-1}(t, V) \leq V \leq \ell_{n-2}^{-1} \Theta_{n-1}(t, V)$,

$$
\Theta_{1}(t, V)=\frac{e^{-r(T-t)}}{\gamma\left(\rho_{V S}^{2}-1\right)} \log \frac{H_{1}^{S}\left(t, V e^{\alpha(T-t)} ; \psi_{1}\left(t, \Theta_{2}\right)\right)}{\widehat{H}_{1}^{S}\left(t, V e^{\alpha(T-t)}, \psi_{1}\left(t, \Theta_{2}\right)\right)},
$$

for $V \geq \ell_{1}^{-1} \Theta_{1}(t, V)$, where $\left(H_{i}^{S}, i=1,2, \cdots, n\right)$ are solutions of System $(27)-(32)$ and $\left(\widehat{H}_{i}^{S}, i=1,2, \cdots, n\right)$ are solutions of System (33)-(38), whose explicit formulas are given in Lemma 3. Suppose that the bond holder hedges the credit risk of the corporate bond by trading the financial index. Then, the prices of the corporate bond $\left(\Theta_{i}, i=1,2, \cdots, n\right)$ satisfy:

$$
\Theta_{n}(t, V)=\frac{e^{-r(T-t)}}{\gamma\left(\rho_{V P}^{2}-1\right)} \log H_{n}^{P}\left(t, V e^{\alpha(T-t)}\right)-\frac{\left(\mu_{P}-r\right)^{2}}{2 \sigma_{P}^{2} \gamma} e^{-r(T-t)}(T-t),
$$

for $D e^{-\alpha(T-t)} \leq V \leq \ell_{n-1}^{-1} \Theta_{n}(t, V)$,

$$
\Theta_{n-1}(t, V)=\frac{e^{-r(T-t)}}{\gamma\left(\rho_{V P}^{2}-1\right)} \log H_{n-1}^{P}\left(t, V e^{\alpha(T-t)} ; \psi_{n-1}\left(t, \Theta_{n}\right)\right)-\frac{\left(\mu_{P}-r\right)^{2}}{2 \sigma_{P}^{2} \gamma} e^{-r(T-t)}(T-t),
$$

for $\ell_{n-1}^{-1} \Theta_{n-1}(t, V) \leq V \leq \ell_{n-2}^{-1} \Theta_{n-1}(t, V)$, 


$$
\Theta_{1}(t, V)=\frac{e^{-r(T-t)}}{\gamma\left(\rho_{V P}^{2}-1\right)} \log H_{1}^{P}\left(t, V e^{\alpha(T-t)} ; \psi_{1}\left(t, \Theta_{2}\right)\right)-\frac{\left(\mu_{P}-r\right)^{2}}{2 \sigma_{P}^{2} \gamma} e^{-r(T-t)}(T-t),
$$

for $V \geq \ell_{1}^{-1} \Theta_{1}(t, V)$, where $\left(H_{i}^{P}, i=1,2, \cdots, n\right)$ are solutions of System (39)-(44), whose explicit formulas are given in Lemma 3.

Proof. The results are easily derived by using the utility indifference pricing principles (3) and (5). In addition, as $\left(H_{i}^{S}, i=1,2, \cdots, n\right),\left(\widehat{H}_{i}^{S}, i=1,2, \cdots, n\right)$ and $\left(H_{i}^{P}, i=1,2, \cdots, n\right)$ are continuous across the credit rating migration boundaries, the price of the bond $\left(\Theta_{i}, i=1,2, \cdots, n\right)$ is also continuous across the credit rating migration boundaries, i.e.,

$$
\Theta_{i}(t, V)=\Theta_{i+1}(t, V), i=1,2, \cdots, n-1,
$$

on the credit rating migration boundaries.

Proposition 1. The credit rating regions in Theorem 1 given as:

$$
\begin{gathered}
D e^{-\alpha(T-t)} \leq V \leq \ell_{n-1}^{-1} \Theta_{n}(t, V), \\
\ell_{n-1}^{-1} \Theta_{n-1}(t, V) \leq V \leq \ell_{n-2}^{-1} \Theta_{n-1}(t, V), \\
\cdots \\
\ell_{2}^{-1} \Theta_{2}(t, V) \leq V \leq \ell_{1}^{-1} \Theta_{2}(t, V), \\
\ell_{1}^{-1} \Theta_{1}(t, V) \leq V<\infty,
\end{gathered}
$$

can be rewritten as:

$$
\begin{gathered}
D e^{-\alpha(T-t)} \leq V \leq V_{n-1}^{S}(t)\left(\text { or } D e^{-\alpha(T-t)} \leq V \leq V_{n-1}^{P}(t)\right), \\
V_{n-1}^{S}(t) \leq V \leq V_{n-2}^{S}(t)\left(\text { or } V_{n-1}^{P}(t) \leq V \leq V_{n-2}^{P}(t)\right), \\
\cdots \\
V_{2}^{S}(t) \leq V \leq V_{1}^{S}(t)\left(\text { or } V_{2}^{P}(t) \leq V \leq V_{1}^{P}(t)\right), \\
V_{1}^{S}(t) \leq V \leq \infty\left(\text { or } V_{1}^{P}(t) \leq V<\infty\right),
\end{gathered}
$$

where $\left\{V_{i}^{S}, V_{i}^{P}, i=1,2, \cdots, n-1\right\}$ are the credit rating migration boundaries. $V_{i}^{S}$ stands for those in the situation that investors hedge credit risk by trading the firm's stock, while $V_{i}^{P}$ stands for those in the situation that investors trade the financial index.

The existence of credit rating migration boundaries $\left\{V_{i}^{S}, V_{i}^{P}, i=1,2, \cdots, n-1\right\}$ is achieved by using the implicit function theorem (see Appendix B). Hence, their explicit formulas cannot be derived.

\section{Conclusions}

In this paper, we devote our study to the corporate bond valuation with default probability possibly happening at any moment before maturity and the credit rating migration probability. We work under the structural framework, where the default follows Black and Cox's assumption and the credit rating migration follows the assumption that the credit rating migrates over the dynamic proportion of the firm's debt and asset value. As the market is supposed to be incomplete, then the utility indifference pricing methodology is used. Two representative assets are selected to hedge the credit risk and determine the utility indifferent price of the corporate bond, the stock issued by the 
firm itself, and a financial index from the market. The financial index is supposed to be independent of the firm's liquidation and can be traded continuously after the firm collapses, which is different from investing in the firm's stock. Thus, these two hedging strategies lead to different prices of the corporate bond. We present the explicit formulas for the indifferent prices of the corporate bond with default and credit rating migration in these two hedging strategies. Investors can analyze the effects of default and credit rating migration on the bond prices and credit spreads by our pricing formulas and easily test the sensibility of price with regard to the changes of parameters. In addition, the investors can compare the difference in prices in the two hedging strategies and generate their investment decisions by the credit information and price information involved in our explicit pricing formulas of the corporate bonds.

The multiplicity of credit rating migration really causes some difficulties for us to derive the closed-form solutions of the bond pricing formulas. However, this is solved by following Black and Cox's assumption and introducing a default boundary and an inverted iteration program. Finally, we prove the existence of the credit rating migration boundaries by the implicit function theorem. However, we cannot obtain their explicit formulas as functions of time. We have to acknowledge that this is a limitation of our results.

Author Contributions: Conceptualization, Z.H.; methodology, Z.H.; validation, Z.H., Z.L., and Z.W.; formal analysis, Z.L.; investigation, Z.W.; resources, Z.H.; writing, original draft preparation, Z.W.; writing, review and editing, Z.H.; supervision, Z.L.; project administration, Z.H.; funding acquisition, Z.H. All authors read and agreed to the published version of the manuscript.

Funding: This research was funded by National Natural Science Foundation of China Grant Number 11701115.

Conflicts of Interest: The authors declare no conflict of interest.

\section{Appendix A. Proof of Lemma 1}

We only take $U_{n}^{S}$ for example. The others are parallel to $U_{n}^{S}$. Define the domain:

$$
\mathscr{D}=\left\{(t, W, V): D_{t} \leq V \leq \gamma_{n-1}^{-1} \Theta_{t}\right\}
$$

$\tau_{D}$ is the first moment of escaping the default boundary for $V_{t}$, and $\tau_{n}$ is the first moment escaping the credit rating migration boundary. Then, for any given point $(t, W, V) \in \mathscr{D}$, two strategies are executed in the period $[t, T]$, where one applies the optimal strategy $\pi^{*}$ and the other is given as:

$$
\hat{\pi}^{*}=c \text { for } s \in[t, t+h], \hat{\pi}^{*}=\pi^{*} \text { for } s \in(t+h, T],
$$

where $c$ is a constant. The expected utility is given as:

$$
\begin{aligned}
\mathbb{E} & {\left[U_{n}^{S}\left(t+h, W_{t+h}^{S}, V_{t+h}\right)+U_{n}^{S}\left(\tau_{n}, W_{\tau_{n}}^{S}, V_{\tau_{n}}\right) 1_{\left\{\tau_{n}<\min \left\{\tau_{D}, t+h\right\}\right\}}\right.} \\
& \left.+U_{n}^{S}\left(\tau_{D}, W_{\tau_{D}}^{S}, V_{\tau_{D}}\right) 1_{\left\{\tau_{D}<\min \left\{\tau_{n}, t+h\right\}\right.} \mid W_{t}^{S}=W, V_{t}=V\right] .
\end{aligned}
$$

In the first case, suppose that $V_{t}$ does not escape either the default boundary or the credit rating migration boundary, i.e., $t<\min \left\{\tau_{D}, \tau_{n}\right\}$. Therefore, it holds that $t+h<\min \left\{\tau_{D}, \tau_{n}\right\}$ as long as $h$ is sufficiently small. Take the conditional expectation of the Itô formula of $U_{n}^{S}\left(t+h, W_{t+h}^{S}, V_{t+h}\right)$; we have:

$$
\begin{aligned}
& \mathbb{E}\left[U_{n}^{S}\left(t+h, W_{t+h}^{S}, V_{t+h}\right) \mid W_{t}^{S}=W, V_{t}=V\right] \\
= & U_{n}^{S}\left(t, W_{t}^{S}, V_{t}\right)+\int_{t}^{t+h} \mathbb{E}\left[\left(U_{n}^{S}\right)_{S}+\mathscr{L}_{n}^{S} U_{n}^{S} \mid W_{t}^{S}=W, V_{t}=V\right] d s .
\end{aligned}
$$


By the dynamic programming theory, which means that the expected utility under the optimal strategy is no less than any other strategies, it holds that:

$$
\int_{t}^{t+h} \mathbb{E}\left[\left(U_{n}^{S}\right)_{s}+\mathscr{L}_{n}^{S} U_{n}^{S} \mid W_{t}^{S}=W, V_{t}=V\right] d s \leq 0
$$

Dividing (A1) by $h$ and letting $h$ tend to zero, we have:

$$
\sup _{\pi \in \mathcal{A}_{a d}}\left\{\left(U_{n}^{S}\right)_{t}+\mathscr{L}_{n}^{S} U_{n}^{S}\right\} \leq 0
$$

On the other hand, the property of the supremum gives:

$$
\sup _{\pi \in \mathcal{A}_{a d}}\left\{\left(U_{n}^{S}\right)_{t}+\mathscr{L}_{n}^{S} U_{n}^{S}\right\} \geq 0
$$

which claims the HJB equation (8) in the lowest credit rating region. In the second case, if $t=T$, then it holds that:

$$
U_{n}^{S}(T, W, V)=-\exp (-\gamma(W+F)) .
$$

In the third case, we consider the point at the default boundary, i.e., $t=\tau_{D}<\min \left\{\tau_{n}, T\right\}$. By the continuity of Brownian motion and the default threshold $D_{t}$, we have:

$$
U_{n}^{S}\left(t, W_{t}^{S}, D_{t}\right)=-\exp \left(-\gamma e^{r(T-t)}\left(W_{t}^{S}+\omega D_{t}\right)\right) .
$$

In the fourth case, on the credit rating migration boundary, i.e., $t=\tau_{n}<\min \left\{\tau_{D}, T\right\}$, again by the continuity of Brownian motion, we have:

$$
U_{n}^{S}(t, W, V)=U_{n}^{S}\left(\tau_{n}, W_{\tau_{n}}^{S}, V_{\tau_{n}}\right)=U_{n-1}^{S}\left(\tau_{n}, W_{\tau_{n}}^{S}, V_{\tau_{n}}\right)=U_{n-1}^{S}(t, W, V) .
$$

\section{Appendix B. Proof of Proposition 1}

Denote by:

$$
F_{i}(t, V)=\Theta(t, V)-\ell_{i} V, i=1,2, \cdots, n-1 .
$$

Let $\left(t_{0}, V_{0}\right)$ be in the credit rating migration boundaries, i.e., for some $1 \leq i \leq n-1$, it holds that:

$$
F_{i}\left(t_{0}, V_{0}\right)=\Theta\left(t_{0}, V_{0}\right)-\ell_{i} V_{0}=0 .
$$

If the bond holder hedges the credit risk of the corporate bond by trading the stock. Then, (A2) implies that:

$$
H_{i}^{S}\left(t_{0}, V_{0} e^{\alpha\left(T-t_{0}\right)}\right)=\exp \left(\gamma\left(\rho_{V S}^{2}-1\right) \ell_{i} e^{r\left(T-t_{0}\right)} V_{0}\right) \widehat{H}_{i}^{S}\left(t_{0}, V_{0} e^{\alpha\left(T-t_{0}\right)}\right) .
$$

On the other hand, we have:

$$
\begin{aligned}
\left.\left(F_{i}(t, V)\right)_{V}\right|_{t=t_{0}, V=V_{0}}= & \left.\Theta_{V}(t, V)\right|_{t=t_{0}, V=V_{0}}-\ell_{i} \\
= & \left.\frac{e^{-r\left(T-t_{0}\right)}}{\gamma\left(\rho_{V S}^{2}-1\right)} \frac{\widehat{H}_{i}^{S}\left(t_{0}, V_{0} e^{\alpha\left(T-t_{0}\right)}\right)}{H_{i}^{S}\left(t_{0}, V_{0} e^{\alpha\left(T-t_{0}\right)}\right)}\left(\frac{H_{i}^{S}\left(t, V e^{\alpha(T-t)}\right)}{\widehat{H}_{i}^{S}\left(t, V e^{\alpha(T-t)}\right)}\right)_{V}\right|_{t=t_{0}, V=V_{0}} \\
& -\ell_{i} \\
= & \left.\frac{\exp \left(-r\left(T-t_{0}\right)-\gamma\left(\rho_{V S}^{2}-1\right) \ell_{i} e^{r\left(T-t_{0}\right)} V_{0}\right)}{\gamma\left(\rho_{V S}^{2}-1\right)}\left(\frac{H_{i}^{S}\left(t, V e^{\alpha(T-t)}\right)}{\widehat{H}_{i}^{S}\left(t, V e^{\alpha(T-t)}\right)}\right)_{V}\right|_{t=t_{0}, V=V_{0}} \\
& -\ell_{i} .
\end{aligned}
$$


Thus, $\left.\left(F_{i}(t, V)\right)_{V}\right|_{t=t_{0}, V=V_{0}}=0$ is equivalent to:

$$
\left.\left(\frac{H_{i}^{S}\left(t, V e^{\alpha(T-t)}\right)}{\widehat{H}_{i}^{S}\left(t, V e^{\alpha(T-t)}\right)}\right)_{V}\right|_{t=t_{0}, V=V_{0}}=\gamma\left(\rho_{V S}^{2}-1\right) \ell_{i} e^{r\left(T-t_{0}\right)} \exp \left(\gamma\left(\rho_{V S}^{2}-1\right) \ell_{i} e^{r\left(T-t_{0}\right)} V_{0}\right) .
$$

However, the formulas of $H_{i}^{S}(t, y)$ and $\widehat{H}_{i}^{S}(t, y)$ imply that the left-hand side of (A3) cannot be the exponent of $V_{0}$, i.e., $\left.\left(F_{i}(t, V)\right)_{V}\right|_{t=t_{0}, V=V_{0}} \neq 0$. Thus, by the implicit function theorem, there exists a function $V_{i}^{S}$ such that:

$$
V=V_{i}^{S}(t) \text { for } 0 \leq t \leq T .
$$

Similarly, if the bond holder hedges the credit risk of the corporate bond by trading the financial index, we have:

$$
H_{i}^{P}\left(t_{0}, V_{0} e^{\alpha\left(T-t_{0}\right)}\right)=\exp \left(\left(\ell_{i} V_{0}+\frac{\left(\mu_{P}-r\right)^{2}}{2 \sigma_{P}^{2} \gamma} e^{-r\left(T-t_{0}\right)}\left(T-t_{0}\right)\right) \gamma\left(\rho_{V P}^{2}-1\right) e^{r\left(T-t_{0}\right)}\right),
$$

and:

$$
\begin{aligned}
\left.\left(F_{i}(t, V)\right)_{V}\right|_{t=t_{0}, V=V_{0}} & =\left.\Theta_{V}(t, V)\right|_{t=t_{0}, V=V_{0}}-\ell_{i} \\
& =\left.\frac{e^{-r\left(T-t_{0}\right)}}{\gamma\left(\rho_{V P}^{2}-1\right)} \frac{1}{H_{i}^{P}\left(t_{0}, V_{0} e^{\alpha\left(T-t_{0}\right)}\right)}\left(H_{i}^{P}\left(t, V e^{\alpha(T-t)}\right)\right)_{V}\right|_{t=t_{0}, V=V_{0}}-\ell_{i} .
\end{aligned}
$$

Thus, $\left.\left(F_{i}(t, V)\right)_{V}\right|_{t=t_{0}, V=V_{0}}=0$ is equivalent to:

$$
\begin{aligned}
& \left.\left(H_{i}^{P}\left(t, V e^{\alpha(T-t)}\right)\right)_{V}\right|_{t=t_{0}, V=V_{0}} \\
= & \ell_{i} \gamma\left(\rho_{V P}^{2}-1\right) e^{r\left(T-t_{0}\right)} \exp \left(\left(\ell_{i} V_{0}+\frac{\left(\mu_{P}-r\right)^{2}}{2 \sigma_{P}^{2} \gamma} e^{-r\left(T-t_{0}\right)}\left(T-t_{0}\right)\right) \gamma\left(\rho_{V P}^{2}-1\right) e^{r\left(T-t_{0}\right)}\right) .
\end{aligned}
$$

However, the formulas of $H_{i}^{P}(t, y)$ imply that the left-hand side of (A4) also cannot be the exponent of $V_{0}$, i.e., $\left.\left(F_{i}(t, V)\right)_{V}\right|_{t=t_{0}, V=V_{0}} \neq 0$. Thus, by the implicit function theorem, there exists a function $V_{i}^{P}$ such that:

$$
V=V_{i}^{P}(t) \text { for } 0 \leq t \leq T .
$$

\section{References}

1. Dereeper, S.; Lobez, F.; Statnik, J.C. Bank credit rates across the business cycle: Evidence from a French cooperative contracts database. J. Bank. Financ. 2020, 112, 105220. [CrossRef]

2. Jang, B.; Rhee, Y.; Yoon, J. Business cycle and credit risk modeling with jump risks. J. Empir. Financ. 2016, 39, 15-36. [CrossRef]

3. Mertzanis, C. Complexity, big data and financial stability. Quant. Financ. Econ. 2018, 2, 637-660. [CrossRef]

4. Dolfin, M.; Knopoff, D.; Limosani, M.; Xibilia, M.G. Credit risk contagion and systemic risk on networks. Mathematics 2019, 7, 713. [CrossRef]

5. Holod, D.; Kitsul, Y.; Torna, G. Market risk-based capirtal requirements, trading activity, and bank risk. J. Bank. Financ. 2020, 112, 105202. [CrossRef]

6. Kolokolova, O.; Lin, M.T.; Poon, S.H. Too big to ignire? Hedge fund flows and bond yields. J. Bank. Financ. 2020, 112, 105271. [CrossRef]

7. Le Courtois, O.; Nakagawa, H. On surrender and default risks. Math. Financ. 2013, 23, 143-168. [CrossRef]

8. Lizarazo, S.V. Default risk and risk averse international investors. J. Int. Econ. 2013, 89, 317-330. [CrossRef]

9. Loffler, A. Measuring corporate default risk. J. Econ. 2012, 106, 97-98.

10. Fei, F.; Fuertes, A.M.; Kalotychou, E. Credit Rating Migration Risk and Business Cycles. J. Bus. Financ. Account. 2012, 39, 229-263. [CrossRef]

11. Farnsworth, H.; Li, T. The dynamics of credit spreads and ratings migration. J. Financ. Quant. Anal. 2007, 42, 595-620. [CrossRef] 
12. Yan, D.; Zhang, X.; Wang, M. A robust bank asset allocation model integrating credit-rating migration risk and capital adequacy ratio regulations. Ann. Oper. Res. 2020. [CrossRef]

13. Boninghausen, B.; Zabel, M. Credit ratings and cross-border bond market spillovers. J. Int. Money Financ. 2015, 53, 115-136. [CrossRef]

14. Kariya, T.; Yamamura, Y.; Inui, K. Empirical credit risk ratings of individual corporate bonds and derivation of term structures of default probabilities. J. Risk Financ. Manag. 2019, 12, 124. [CrossRef]

15. Livingston, M.; Poon, W.P.H.; Zhou, L. Are Chinese credit ratings relevant? A study of the Chinese bond market and credit rating industry. J. Bank. Financ. 2018, 87, 216-232. [CrossRef]

16. Hodges, S.; Neuberger, A. Optimal replication of contingent claims under transaction costs. Rev. Future Mark. 1989, 8, 222-239.

17. Merton, R.C. On the pricing of corporate debt: The risk structure of interest rates. J. Financ. 1974, 29, 449-470.

18. Black, F.; Cox, J.C. Valuing Corporate Securities: Some Effects of Bond Indenture Provisions. J. Financ. 1976, 31, 351-367. [CrossRef]

19. Liang, G.; Jiang, L. A modified structural model for credit risk. IMA J. Manag. Math. 2012, 23, 147-170. [CrossRef]

20. Liang, J.; Zhao, Y.; Zhang, X. Utility indifference valuation of corporate bond with credit rating migration by structure approach. Econ. Model. 2016, 54, 339-346. [CrossRef]

21. Hu, B.; Liang, J.; Wu, Y. A free boundary problem for corporate bond with credit rating migration. J. Math. Anal. Appl. 2015, 428, 896-909. [CrossRef]

22. Liang, J.; Wu, Y.; Hu, B. Asymptotic traveling wave solution for a credit rating migration problem. J. Differ. Equ. 2016, 261, 1017-1045. [CrossRef]

23. Baranoff, E.G.; Brockett, P.; Sager, T.W.; Shi, B. Was the U.S. life insurance industry in danger of systemic risk by using derivative hedging prior to the 2008 financial crisis? Quant. Financ. Econ. 2019, 3, 145-164. [CrossRef]

24. Henderson, V. Valuation of claims on nontraded assets using utility maximization. Math. Financ. 2002, 12, 351-373. [CrossRef]

25. Musiela, M.; Zariphopoulou, T. An example of indifference prices under exponential preferences. Financ. Stoch. 2004, 2, 229-239. [CrossRef]

26. Zariphopoulou, T. A solution approach to valuation with unhedgeable risks. Financ. Stoch. 2001, 5, 61-82. [CrossRef]

27. Porchet, A.; Touzi, N.; Warin, X. Valuation of power plants by utility indifference and numerical computation. Math. Methods Oper. Res. 2009, 70, 47-75. [CrossRef]

28. Benedetti, G.; Campi, L. Utility indifference valuation for non-smooth payoffs with an application to power derivatives. Appl. Math. Optim. 2016, 73, 349-389. [CrossRef]

29. Li, P.; Lu, X.; Zhu, S. Pricing weather derivatives with the market price of risk extracted from the utility indifference valuation. Comput. Math. Appl. 2020, 79, 3394-3409. [CrossRef]

30. Duffe, D.; Singleton, K.J. Modeling termstructures of defaultable bonds. Rev. Financ. Stud. 1999, 12, 687-720. [CrossRef]

31. Jarrow, R.; Turnbull, S. Pricing derivatives on financial securities subject to credit risk. J. Financ. 1995, 50, 53-85. [CrossRef]

32. Jarrow, R.A.; Lando, D.; Turnbull, S.M. A Markov model for the term structure of credit risk spreads. Rev. Financ. Stud. 1997, 10, 481-523. [CrossRef]

33. Lando, D. On Cox processes and credit-risky securities. Rev. Deriv. Res. 1998, 2, 99-120. [CrossRef]

34. Leland, H. Corporate debt value, bond covenants, and optimal capital structure. J. Financ. 1994, 49, $1213-1252$. [CrossRef]

35. Longstaff, F.; Schwartz, E. A simple approach to valuing risky fixed and floating rate debt. J. Financ. 1995, 50, 789-819. [CrossRef]

36. Leland, H.; Toft, K.B. Optimal capital structure, endogenous bankruptcy, and the term strcuture of credit spreads. J. Financ. 1996, 51, 987-1019. [CrossRef]

37. Briys, E.; de Varenne, F. Valuing risky fixed rate debt: An extension. J. Financ. Quant. Anal. 1997, 32, $239-249$. [CrossRef]

38. d'Amico, G.; Di Biase, G.; Janssen, J.; Manca, R. Semi-Markov Migration Models for Credit Risk; Wiley-ISTE: London, UK, 2017. 
39. Frydman, H.; Schuermann, T. Credit Rating Dynamics and Markov Mixture Models. J. Bank. Financ. 2008, 32, 1062-1075. [CrossRef]

40. Das, S.; Tufano, P. Pricing credit-sensitive debt when interest rates, credit ratings, and credit spreads are stochastic. J. Financ. Eng. 1996, 5, 161-198.

41. Thomas, L.C.; Allen, D.E.; Morkelkingsbury, N. A hidden Markov chain model for the term structure of bond credit risk spreads. Int. Rev. Financ. Anal. 2002, 11, 311-329. [CrossRef]

42. Liang, J.; Yin, H.M.; Chen, X.; Wu, Y. On a corporate bond pricing model with credit rating migration risks and stochastic interest rate. Qual. Financ. Econ. 2017, 1, 300-319. [CrossRef]

43. Yin, H.; Liang, J.; Wu, Y. On a new corporate bond pricing model with potential credit rating change and stochastic interest rate. J. Risk Financ. Manag. 2018, 11, 87. [CrossRef]

44. Liang, Y.; Xu, C. An effcient conditional Monte Carlo method for European option pricing with stochastic volatility and stochastic interest rate. Int. J. Comput. Math. 2020, 97, 638-655. [CrossRef]

45. Pedersen, H.; Swanson, N.R. A survey of dynamic Nelson-Siegel models, diffusion indexes, and big data methods for predicting interest rates. Quant. Financ. Econ. 2019, 3, 22-45. [CrossRef]

46. Wu, Y.; Liang, J. A new model and its numerical method to identify multi credit migration boundaries. Int. J. Comput. Math. 2018, 95, 1688-1702. [CrossRef]

47. Wu, Y.; Liang, J. Free boundaries of credit rating migration in switching macro regions. Math. Control Relat. Fields 2020, 10, 257-274. [CrossRef]

48. Wu, Y.; Liang, J.; Hu, B. A free boundary problem for defaultable corporate bond with credit rating migration risk and its asymptotic behavior. Discret. Contin. Dyn. Syst. B 2020, 25, 1043-1058. [CrossRef]

49. Wang, Z.; Liu, Z.; Jiang, T.; Huang, Z. Asymptotic traveling wave for a pricing model with multiple credit rating migration risk. Commun. Math. Sci. 2019, 17, 1975-2004. [CrossRef]

50. Huang, Z.; Jiang, T.; Wang, Z. On a multiple credit rating migration model with stochastic interest rate. Math. Methods Appl. Sci. 2020, 43, 7106-7134. [CrossRef]

51. Huang, Z.; Miao, Y.; Wang, Z. Free boundary problem pricing defaultable corporate bonds with multiple credit rating migration risk and stochastic interest rate. AIMS Math. 2020, 5, 7746-7775. [CrossRef]

52. Liang, J.; Zou, H. Valuation of credit contingent interest rate swap with credit rating migration. Int. J. Comput. Math. 2020. [CrossRef]

53. Aivazian, V.A.; Callen, J.L.; Krinsky, I.; Kwan, C.C.Y. Mean-Variance Utility Functions and the Demand for Risky Assets: An Empirical Analysis Using Flexible Functional Forms. J. Financ. Quant. Anal. 1983, 18, 411-424. [CrossRef]

54. Phan, D.H.; Sharma, S.S.; Narayan, P.K. Stock return forecasting: Some new evidence. Int. Rev. Financ. Anal. 2015, 40, 38-51. [CrossRef]

55. Westerlund, J.; Narayan, P.K. Does the choice of estimator matter when forecasting returns. J. Bank. Financ. 2012, 36, 2632-2640. [CrossRef]

Publisher's Note: MDPI stays neutral with regard to jurisdictional claims in published maps and institutional affiliations.

(C) 2020 by the authors. Licensee MDPI, Basel, Switzerland. This article is an open access article distributed under the terms and conditions of the Creative Commons Attribution (CC BY) license (http:/ / creativecommons.org/licenses/by/4.0/). 